\title{
Zur Cytologie der Rectaldrüsen von Knorpelfischen
}

\author{
II. Teil : Die Mikromorphologie des zentralen Sammelkanals
}

\author{
W. Stockem, H. Komnick und K. E. Wohlfarth-Bottermann \\ Institut für Cytologie und Mikromorphologie der Universität Bonn, Bonn-Endenich
}

\begin{abstract}
On the cytology of rectal glands of elasmobranchs. Part II: The micromorphology of the central collecting duct. The stratified epithelium of the central collecting duct of the elasmobranch (Scylliorbinus canicula, Galeorbinus galens and Raja batis) rectal gland consists of 3 to 6 layers of cells: one superficial, and several basal cell layers. In the superficial layer normally three different types of cells can be distinguished (a) goblet cells, (b) cells with apical secretory granules and (c) flask-shaped cells. The superficial layer of Scylliorbinus canicula reveals a further cell type, so-called mitochondria-rich cells. The epithelial areas built by these cells are always single-layered. The goblet-cells are very similar to goblet cells found in the intestine of vertebrates. Their dominant structures are a well developed ergastoplasm, a large Golgi-apparatus and mucous granules compactly filling the apical cell region. The cells with apical secretory granules are columnar or dumbbell shaped. They contain a roughsurfaced endoplasmic reticulum and a well developed Golgi-apparatus. The secretory granules are loosely distributed within the Golgi-field and are arranged in one or more rows just below the cell apex. The flask shaped cells are characterized by a cytoplasm rich in small vesicles. They passes few dictyosomes and several small mitochondria. There is some evidence for endocytotic activity. The mitochondria-rich cells are characterized by lateral cell interdigitations, by a basal labyrinth and by numerous mitochondria. They are similar to the cxcretory cells of rectal gland parenchyma. The cells of the basal epithelium layers are differenciated only to a small extent. They are joined in a loose formation with white blood cells often found in the intercellular spaces. The function of the elasmobranch rectal gland is not restricted to the excretion of concentrated salt solutions. There is also a significant secretion of mucous substances. The tubule glands are primarily excretory, the epithelium cells of the central collecting duct mainly secretory in function.
\end{abstract}

\section{EINLEITUNG}

Die Rectaldrüse der Knorpelfische hat in jüngster Zeit erneut die Aufmerksamkeit der Morphologen auf sich gelenkt (Bernard \& Hartman 1960, Dorle 1962, Bulger 1961, 1963, 1965, KoMNICK 1965a, \& b, KoMNick \& WOHLFARTH-BOTTERMANN 1966), nachdem von Burger \& Hess (1960, vgl. auch Burger 1962) beim Dornhai eine exkretorische Funktion dieses Organs nachgewiesen wurde. Die Rectaldrüse des Dornhaies scheidet Kochsalzlösungen aus, deren Konzentration etwa doppelt so groß ist wie die des Blutplasmas und etwas größer als die des Seewassers, und dient somit wahrscheinlich der Osmoregulation (BURGER \& Hess 1960). Neben den Tränendrüsen 
von Reptilien und den Nasendrüsen von Seevögeln (vgl, zusammenfassende Darstellungen von ScHMIDT-NIELSEN 1960 und 1965) ist die Rectaldrüse von Knorpelfischen der dritte bisher bekanntgewordene Fall von Salzdrüsen bei Wirbeltieren. Die Salzausscheidung gilt anscheinend heute bereits als die einzige Funktion dieses Organs, obwohl in der älteren Literatur (vgl. JACOBSHAGEN 1937, BARRINGTON 1957, BERTIN 1958) die verschiedensten Funktionen der Rectaldrüse - wenn auch mit betonter Unsicherheit - genannt werden. So hat beispielsweise Bulger (1965), die unseres Wissens als erste die Feinstruktur des zentralen Sammelkanalepithels der Rectaldrüse von Dornhaien untersucht hat, ihre cytologischen Befunde ausschließlich im Hinblick auf die exkretorische Funktion diskutiert. Bulger erörtert die Frage, ob das Epithel des Zentralkanals, der die durch die Drïsenschläuche ausgeschiedene Salzlösung sammelt und in den Enddarm ableitet, lediglich als strukturelle Diffusionsbarriere einen nachträglichen Konzentrationsausgleich mit den Körperflüssigkeiten verhindert oder ob es durch aktive Transportvorgänge die Zusammensetzung des Exkrets noch verändert und damit an der Exkretionsleistung des Organs unmittelbar teilhat.

Angesichts der zahlreichen, mit Sekrettropfen beladenen Zellen, die den zentralen Sammelkanal der Rectaldrüse von Grundhaien säumen, haben wir bereits kurz darauf hingewiesen (KomNick 1965b), daß die Rectaldrüse neben der Salzausscheidung offenbar auch sekretorische Aufgaben erfüllt. Nachdem wir in einer vorausgegangenen $\mathrm{Pu}-$ blikation den Epithelbau der exkretorischen Rectaldrüsentubuli behandelt haben (Komnick \& Wohlfarth-Bottermann 1966), soll hier die Feinstruktur des Zentralkanalepithels beschrieben werden, um damit unsere cytologischen Kenntnisse über die Rectaldrüse zu erweitern und gleichzeitig zur Klärung der funktionellen Bedeutung dieses Organs beizutragen.

\section{MATERIAL UND METHODEN}

Zur Untersuchung diente die Rectaldrüse von Grundhaien (Galeorbinus galeus) und Glattrochen (Raja batis) aus der Nordsee sowie von Katzenhaien (Scylliorhinus canicula) aus der Nordsee und aus dem Mittelmeer. Die Grundhaie wurden mit der Angel gefangen, und ihre Rectaldrüsen entweder unmittelbar nach dem Fang oder nach kurzer Hälterung entnommen und teilweise zusammen mit dem Darmabschnitt, in den der Drüsenausführungsgang einmündet, fixiert. Bei den beiden letztgenannten Arten handelte es sich um junge Exemplare aus dem Aquarium der Biologischen Anstalt Helgoland bzw, aus dem Laboratoire Arago, Banyuls-Sur-Mer.

Li ch t m ikroskopi e: Zur Fixierung dienten das Gemisch nach Bourn und ZenKer (Romeis 1948), sowie Glutaraldehydlösung (SABAtini, Bensch \& BarRnett 1963 ) in folgenden Zusammensetzungen:

(1) $5 \%$ Glutaraldehyd in $0,04 \mathrm{~m}$ Cacodylatpuffer $\mathrm{pH} 7,3$

(2) $10 \%$ Glutaraldehyd und $0,2 \%$ Cetylpyridiniumchlorid in $0,025 \mathrm{~m}$ Veronalacetatpuffer $\mathrm{pH} 7,2$.

(3) $5 \%$ Glutaraldehyd und 0,5\% Cetylpyridiniumchlorid in $50 \%$ Athylalkohol.

(4) $5 \%$ Glutaraldehyd und $0,4 \%$-Amino-Acridinhydrochlorid in $50 \%$ Athylalkohol. 
Cetylpyridiniumchlorid und 5-Amino-Acridinhydrochlorid wurden der Glutaraldehydlösung zugesetzt, da sie von Whliams und Jackson (PEArse 1960) zur Fixation saurer Mucopolysaccharide empfohlen werden. Längs- und Querschnitte der in Paraffin eingebetteten Rectaldrüsen wurden mit Azan (Romers 1948), Toluidinblau, Alcianblau, mit dem Perjodsäure-Schiff-Reagenz nach McManus (PeARse 1960) oder mit kolloidalem Eisen nach HALE (BARKA \& ANDERSON 1963) angefärbt.

Elektron en mikrosk o pie : Für die elektronenmikroskopische Präparation wurden die Rectaldrüsen viermal (im Bereich des Ausführungsganges, des Drüsenanfangs, der Mitte und des Endes) quer durchgeschnitten, um dem Fixierungsmittel freien Zugang zum Zentralkanal zu bieten. Nach der Fixation wurden an den naturgemäß am schnellsten fixierten Schnittflächen jeweils eine Scheibe von 0,5 bis $1 \mathrm{~mm}$ Dicke abgeschnitten und die übrigen Teile verworfen. Zur Fixation wählten wir folgende Lösungen:

(5) $1 \%$ oder $2 \% \mathrm{O}_{3} \mathrm{O}_{4}$ in $\mathrm{K}_{2} \mathrm{Cr}_{2} \mathrm{O}_{7} / \mathrm{KOH}-\mathrm{Puffer} \mathrm{pH} 7,2$ (Wohlfarth-BottermanN 1957).

(6) $10 \%$ Glutaraldehyd in Veronalacetatpuffer $\mathrm{pH} 7,2$, dann $5 \%$ Glutaraldehyd in Veronalacetatpuffer $\mathrm{pH} 7,2$ mehrere Tage, Nachfixierung in $2 \% \mathrm{OsO}_{4} /$ Veronalacetatpuffer $\mathrm{pH} 7,2$.

(7) $5 \%$ Glutaraldehyd in 0,04 m Cacodylatpuffer pH 7,2 (SABAtini, Bensch \& BARRNETT 1963) und

(8) $10 \%$ Glutaraldehyd und $0,2 \%$ Cetylpyridiniumchlorid in $0,025 \mathrm{~m}$ Veronalacetatpuffer $\mathrm{pH} 7,2$ (siehe oben). Teile der in Lösung 8 fixierten Rectaldrüse wurden vor der Nachfixierung mit $1 \% \mathrm{OsO}_{4}$ in Veronalacetatpuffer mit Alcianblau (PeARSE 1960) oder mit kolloidaler Eisenlösung nach HALE mit oder ohne Visualisierung des Eisens durch Kaliumferrocyanid behandelt. Die Entwässerung erfolgte stufenweise in Aceton oder Alkohol, wobei im 70\% igen Entwässerungsmittel eine Stückkontrastierung mit $0,5 \%$ Uranylacetat teils zusammen mit $1 \%$ Phosphorwolframsäure durchgeführt wurde (WOHLfar TH-BOtTERMANN 1957). Die in Vestopal W (Kellenberger, Schwab \& Ryter, 1956), Methacrylat (Newman, Borysko \& SwerdLow 1949) oder Styrol-Methacrylat (Kushrda 1961) eingebetteten Gewebestücke wurden mit einem Ultrotome der Fa. LKB mit Hilfe von Glasmessern geschnitten und in Siemens-Elektronenmikroskopen Typ UM $100 \mathrm{~d}$ bzw. Elmiskop I untersucht.

\section{BEFUNDE}

Der Sammelkanal durchzieht in Längsrichtung das Zentrum der fingerförmigen Rectaldrüse, deren histologischer Aufbau bereits in einer früheren Mitteilung beschrieben wurde (Komnick \& Wohlfarth-BotTermann 1966). Der von Drüsenparenchym umgebene Zentralkanal geht im distalen Teil der Drüse in einen kurzen Ausführgang über, dem Drüsenschläuche fehlen. Dadurch kommt es zu einer stielartigen Verjüngung des Organs. Der Ausführgang durchstößt schließlich die Darmwand und stellt so die Verbindung zum Enddarm her. Das Kaliber des Zentralkanals wechselt sehr stark auch bei Rectaldrüsen etwa gleicher Größe und gleicher Tierart; in einigen Fällen ist der Zentralkanal weitlumig mit fast kreisförmigem Querschnitt und relativ glatter Wand, 

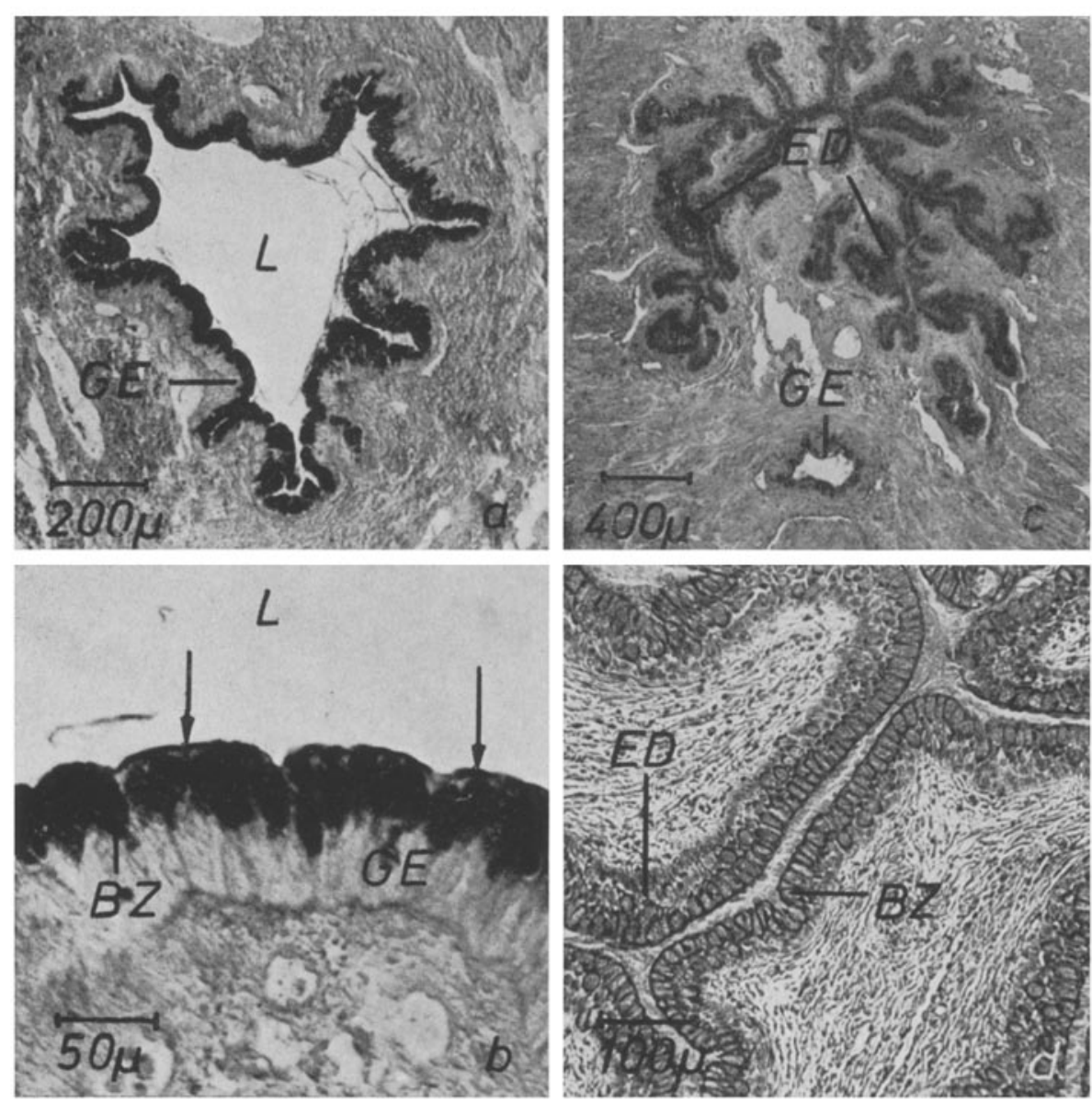

Abb. 1: (a) Galeorbinus galeus; Querschnitt durch den Ausführgang der Rectaldrüse. Das Gangepithel (GE) zeigt starke PAS-Reakrion. $L=$ Lumen des Ausführganges (Bouin; PASReaktion nach McManus. 54:1). (b) Ausschnittvergrößerung aus 1a). Das PAS-positive Material ist in den Becherzellen (BZ) sowie in einer apikalen Granulazone (Pfeilmarkierung) des Gangepithels (GE) lokalisiert. (220:1). (c) Scylliorbinus conicula; Schrägschnitt durch die Enddarmwand im Bereich der Rectaldrüsenmündung. Epithel des Ausführganges (GE) und des Enddarms (ED) mit zahlreichen Becherzellen (Glutaraldehyd, Alcianblau. 28:1). (d) Ausschnittvergrößßerung aus Abbildung 1c. Enddarmepithel (ED) mit Alcianblau-positiven Becherzellen (BZ). (110:1)

in anderen Fällen ist er englumig ${ }^{1}$. Das Lumen selbst kann durch zottenartige Vorwölbung der Wand und auch durch trichterförmige Einstülpungen, die sich weit ins Drüsenparenchym hinein erstrecken, labyrinthartig septiert oder bis auf geringe Reste irisblendenartig verschlossen sein. $\mathrm{Da}$ das Zentralkanalepithel als Ubergangsepithel gilt

1 In der Lichtung des Zentralkanals eines vergleichsweise untersuchten Glatthaies (Mustelus laevis) fanden wir einen offenbar parasitischen Trematoden, dessen Art an Hand der in diesem Falle nidht lïckenlosen Paraffinschnitte nicht bestimmt werden konnte. 
(BULGER 1965), ist es naheliegend, diese Unterschiede auf einen schwankenden Füllungsgrad der Kanallichtung zurückzuführen. Andererseits kann jedoch auch nicht ausgeschlossen werden, daß die Auffaltungen der Zentralkanalwand - zumindest teilweise bei der Abtrennung der Rectaldrüse von der Darmwand durch Kontraktion des peripheren Muskelschlauches entstanden sind. Eine Verkürzung und Verdickung des Organs während der Exstirpation deutet jedenfalls darauf hin.

Bei den untersuchten Arten läßt sich eine weitgehende Ubereinstimmung hinsichtlich des histologischen Aufbaus der Wand des Zentralkanals der Rectaldrüse feststellen. Sie besteht in der Regel aus einem mehrschichtigen Epithel mit mindestens drei, meist jedoch vier bis sechs Zellschichten. Nur in Ausnahmefällen (Katzenhai) kann sie stellenweise auch einschichtig sein.

Nach dem Differenzierungsgrad der Epithelzellen setzen sich deutlich zwei Epithelzonen voneinander $\mathrm{ab}$ (Abb. 1b): Die luminale Epithelseite besteht aus einer Schicht großer und hochdifferenzierter Zellen; die basale Epithelseite ist mehrschichtig und setzt sich aus kleineren und wenig differenzierten Zellen zusammen.

(1) Die luminale oder $s$ uperfizielle Epithelschicht zeigt einen heterogenen Aufbau, an dem insgesamt vier verschiedene Zelltypen beteiligt sind: Becherzellen, Zellen mit apikalen Sekretgrana, sog. Flaschenzellen und mitochondrienreiche Zellen.

(a) B e c h e r z e l l e n konnten bei allen untersuchten Knorpelfischarten gefunden werden. Ihre quantitative Beteiligung am Aufbau der luminalen Schicht des Sammelkanalepithels ist von Art zu Art verschieden, ähnlich wie sie auch im Sammelkanal einer Rectaldrüse selbst keine einheitliche topografische Verteilung zeigen. So ist der Becherzellenbesatz im Zentralkanalepithel der Rectaldrüse des Grundhaies sehr viel dichter als in der Rectaldrüse des Katzenhaies, wo die Becherzellen - vor allem im proximalen Abschnitt - meist nur einzeln oder in Art wenigzelliger Drüsenfelder eingestreut sind. Beim Katzenhai erkennt man in Längsschnitten durch den Zentralkanal ein deutliches zahlenmäßiges Gefälle der Becherzellen entlang der Drüsenlängsachse; der im proximalen Drüsenteil nur spärliche Besatz der Becherzellen wird zum distalen Bereich hin immer dichter. Im Ausführgang bilden sie schließlich eine fast geschlossene Schicht, die an die Becherzellenschicht des Enddarmepithels anschließt (Abb. 1c und d). Auch beim Grundhai ist die dichteste Becherzellenpopulation im distalen Bereich des Sammelkanalepithels sowie im Ausführgang der Rectaldrüse anzutreffen (Abb. 1a und b). Entsprechende Verhältnisse für das Vorkommen von Becherzellen gelten auch beim Glattrochen. Morphologisch besitzen diese Zellen einen hohen Differenzierungsgrad. Der Zellapex ist ein etwa 15 bis $25 \mu$ breiter und 40 bis $50 \mu$ hoher und mit Sekret angefüllter Becher (Abb. 2), dessen Wand aus der Zellmembran und einem zarten Cytoplasmasaum besteht. An den Bechergrund schließt sich basalwärts ein etwa $1 \mu$ dünner Stiel an, der bei günstiger Schnittlage zwischen den intermediären Zellschichten bis zur basalen Zellreihe verfolgt werden kann. Die Gesamthöhe der Zellen beträgt mehrals $70 \mu$.

Entsprechend dieser morphologisch erkennbaren Gliederung in Becher, Bechergrund und Stiel läßt sich eine klare Zuordnung für die Lage der charakteristischen Strukturen innerhalb der Zelle treffen: Der Becher ist dicht mit elektronenoptisch kontrastarmen Grana von 1 bis $3 \mu$ Durchmesser angefüllt, bei denen es sich um Sekret- 


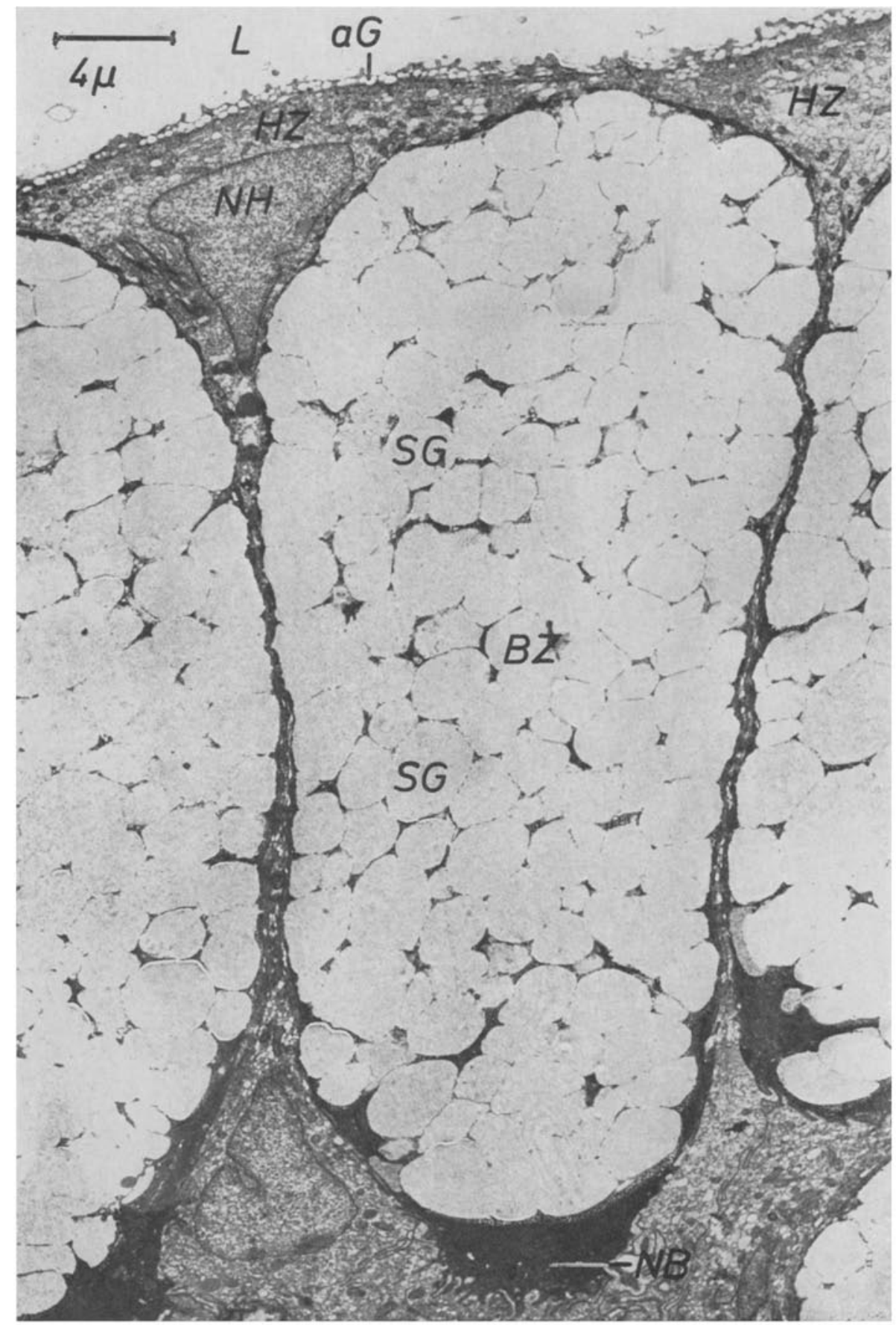

Abb. 2: Raja batis; Längsschnitt durch die luminale Epithelschicht des Zentralkanals der Rectaldrüse mit Becherzellen (BZ) und Zellen mit apikalen Sekretgrana ( $\mathrm{HZ}=$ hantelförmiger Zelltyp). $a \mathrm{G}=$ apikale Granulazone; $\mathrm{SG}=$ Schleimgrana der Becherzelle. NB $=$ Nucleus der Becherzelle; $\mathrm{NH}=$ Nucleus der hantelförmigen Zelle; $\mathrm{L}=$ Lumen des Zentralkanals. $\left(\mathrm{O}_{5} \mathrm{O}_{4} /\right.$ $\mathrm{K}_{2} \mathrm{Cr}_{2} \mathrm{O}_{7}$, Fixierung Nr. 5, Vestopaleinbettung. 3850:1) 
vesikel mit schleimartigem Inhalt handelt (Abb. 2). Diese Schleimtropfen können häufig - möglicherweise auch durch präparativen Einfluß - miteinander konfluieren (Abb. 3). Das Cytoplasma ist in dieser Zellregion bis auf geringe Reste zwischen den Sekrettropfen in Form eines dünnen, den gesamten Becher umgebenden Saumes an die Zellperipherie gedrängt. Der Bechergrund beherbergt den durch ein äußerst dichtes und kontrastreiches Karyoplasma gekennzeichneten und meist polymorph gestalteten Zellkern sowie die Hauptmasse des Golgi-Apparates und des Ergastoplasmas, die von vereinzelten Mitochondrien und Sekrettropfen durchsetzt werden (Abb. 3, 4 und 6). Zahlreiche Dictyosomen bilden dicht aufeinanderfolgend den im Längsschnitt etwa U-förmig darstellbaren komplexen Golgi-Apparat, der die supranucleäre Region beherrscht (Abb. 4 und 6). Nicht unerhebliche Anteile des Golgi-Apparates schieben sich häufig auch zwischen die Sekrettropfen (Abb. 4) und regelmäßig an der Becherwand sehr weit apikalwärts (Abb. 3), so daß räumlich der Golgi-Apparat als eine etwa die untere Hälfte des Bechers umhüllende Kappe gedeutet werden kann. Ein schräger Tangentialschnitt durch diese Kappe (Abb. 5) vermittelt - trotz der ausschnittsweisen Darstellungeinen Eindruck vom Ausmaß des Golgi-Apparates dieser Zellen. An den Golgi-Apparat schließt sich ein lamellär organisiertes Ergastoplasma an, das sich seitlich und basal vom Zellkern konzentriert (Abb. 3) und in der Stielregion verliert. Golgi-Apparat und Ergastoplasma sind die quantitativ dominierenden Cytoplasmastrukturen, wobei der Golgi-Apparat dem Anschein nach leicht überwiegt. Der Bechergrund wird also von den Arbeitsstrukturen besetzt, deren Produkt (das Sekret) im darüberliegenden Becher so stark angehäuft wird, daß es die Arbeitsstrukturen selbst immer mehr zurückdrängt und räumlich einengt. Selbst die Kernoberfläche wird häufig von den Sekrettropfen stark eingedellt (Abb. 3).

Die unmittelbare Umgebung des Golgi-Apparates sowie der zwischen Ergastoplasma und Golgi-Apparat gelegene Raum ist normalerweise dicht mit zahlreichen, etwa 600 bis $900 \AA$ großen Vesikeln angefüllt, denen wahrscheinlich eine 'Transportfunktion zwischen diesen beiden Zellorganellen zukommt (Abb. 4 und 5). Der Strukturaspekt der Dictyosomen selbst läßt auf eine Beteiligung an sekretorischen Prozessen schließen: die vakuolenförmigen peripheren Auftreibungen der nicht selten über $10 \mu$ langen Golgizisternen sprechen in diesem Zusammenhang für Membranvesikulationsvorgänge (Abb. 5). Das Alter der vom Golgi-Komplex gebildeten Sekretvakuolen ist vor allem in jüngeren Becherzellen deutlich an ihrer unterschiedlichen Größe erkennbar, wie aus der in Abbildung 6 näher charakterisierten Vesikelpopulation $\left(S_{1}-S_{4}\right)$ ersichtlich ist. Altere Vakuolen mit reifem Sekret werden schließlich im apikal gelegenen Schleimbecher der Zellen gesammelt.

(b) Z ellen mit a pika len Sekretgrana füllen entweder als prismatische Zellen größere Epithelareale zwischen vereinzelt stehenden Becherzellen aus oder sie liegen in abgewandelten Formen als hantel-oder pilzförmige Zellen in den Zwickeln $z$ wischen den dicht stehenden Becherzellen (Abb. 2 und 7). Dadurch wird das Sammelkanalepithel des Grundhaies zum Lumen hin von einer geschlossenen granulären Zone begrenzt. Beim Katzenhai kann ein solch durchgehender granulärer Saum nicht beobachtet werden, da seine Kontinuität oftmals über weite Strecken durch nichtsekretorische Zellen unterbrochen ist. Der mehr hantel- oder pilzförmige Zelltyp ist durch den durch die räumliche Enge bedingten schlanken Mittelteil sowie durch den verbreiterten 
Zellapex charakterisiert, der die benachbarten Becherzellen so stark iberlappen kann, daß deren freie Oberfläche bis auf eine oft nur wenige $\mu$ messende Offnung verdeckt wird (Abb. 2). Die Zellapices dieses sowie auch des prismatischen Zelltypes tragen einen meist spärlichen Besatz kurzer Mikrovilli. Die apikale Zellmembran wird außen von

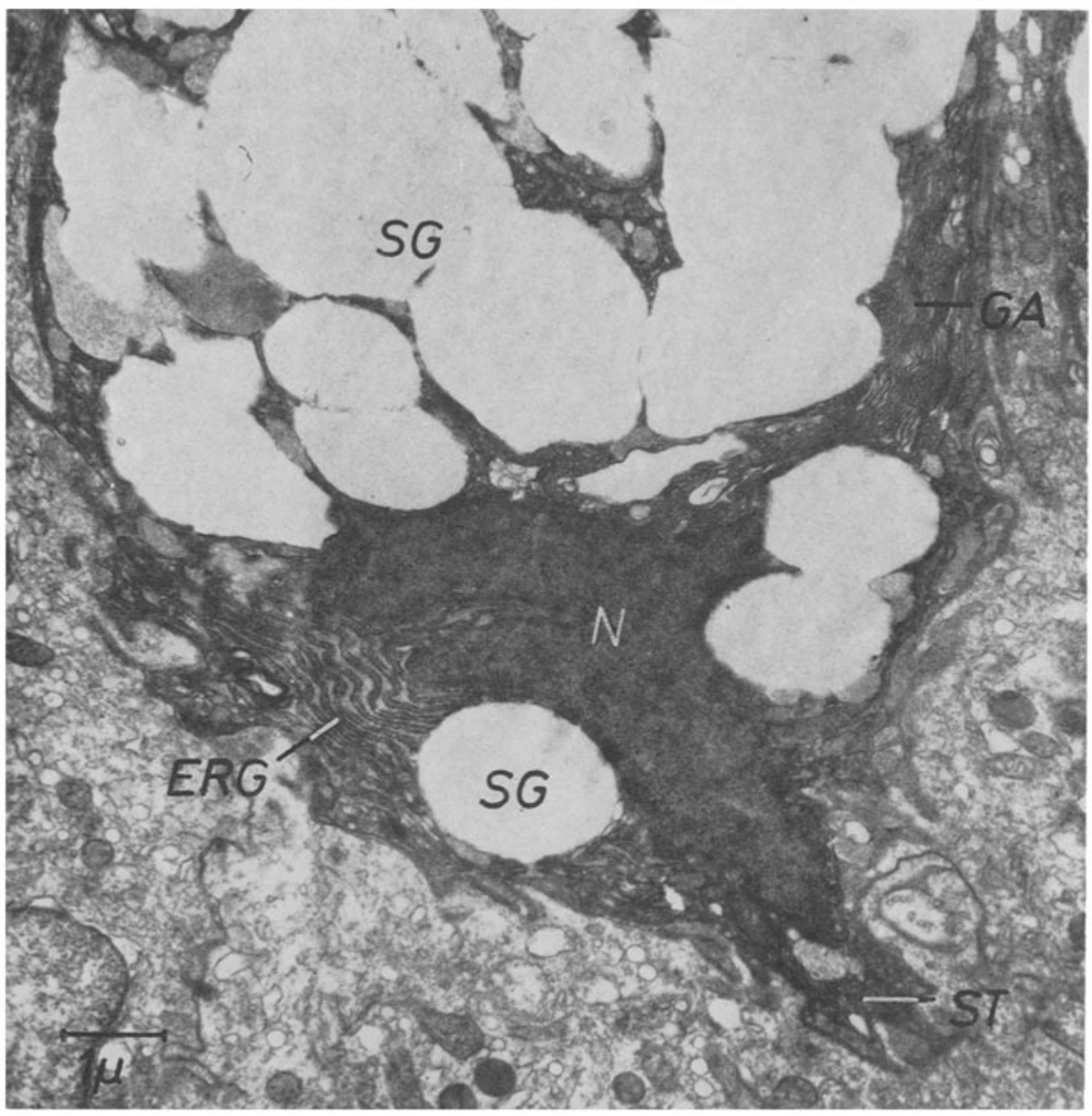

Abb. 3: Raja batis; Ausschnittvergrößerung aus der basalen Region (Bechergrund) einer Becherzelle des Sammelkanalepithels. ERG = Ergastoplasma; GA = Golgi-Apparat; $N=$ Nucleus; $\mathrm{SG}=$ Schleimgrana, $\mathrm{St}=$ schräg getroffener Stielansatz. $\left(\mathrm{O}_{5} \mathrm{O}_{4} / \mathrm{K}_{2} \mathrm{Cr}_{2} \mathrm{O}_{7}\right.$, Fixierung Nr. 5 , Vestopaleinbettung. $10000: 1)$

einem filamentösen, etwa 0,5 bis $1,0 \mu$ dicken Glycocalyx überzogen, der als Produkt der sekretorischen Aktivität der Zellen angesehen werden darf (Abb. 7 und 8). Als intrazelluläre Träger des schleimartigen Sekrets erweisen sich zahlreiche, etwa 0,2 bis $0,5 \mu$ große Vesikel, die in einer (Abb. 7) oder mehreren (Abb. 8) Reihen das unmittelbar unter dem Zellapex gelegene Cytoplasma ausfüllen. Unterhalb dieser Granazone liegen weitere Vesikel geringerer oder gleicher Größe mit ähnlichem Inhalt, die jedoch 
eine entsprechende reihenförmige Anordnung vermissen lassen; sie zeigen vielmehr eine deutliche Lagebeziehung zu einem in der Regel gut entwickelten supranucleär gelegenen Golgi-Apparat, der aus mehreren, reihenförmig angeordneten Dictyosomen besteht (Abb. 7 und 8). Diese Formation der Dictyosomen umschließt nicht selten hufeisenförmig Teile des Zellkerns (Abb. 9). Die Dictyosomen bestehen normalerweise aus 5 bis 10 stark abgeflachten Zisternen, deren periphere, vakuolenförmige Auftreibungen wie im Falle der Becherzellen ebenfalls auf Membranvesikulationsprozesse sowie auf eine Beteiligung an sekretorischen Vorgängen schließen lassen. Abweichend von den in Becherzellen beschriebenen Befunden konnten in Zellen mit apikalen Sekretgrana vereinzelt Golgi-Apparate gefunden werden, die in Flachschnitten eine vom Normaltyp abweichende Struktur zeigen (Abb. 10). Die Dictyosomen werden aus Stapeln flacher, isoliert liegender Zisternen aufgebaut (vgl. Abb. 7 bis 9), die an zahlreichen Stellen porenähnliche Durchbrüche, vergleichbar mit den Verhältnissen in der Kernhülle sowie im Endothel, besitzen. Solche aus gefensterten Zisternen aufgebauten Dictyosomen werden im Tier- und Pflanzenreich häufig angetroffen, ohne daß bis jetzt eine befriedigende Deutung dieser Strukturen gegeben werden konnte (WHALEY 1966).

Während die bereits beschriebenen Sekretvakuolen sowie der stark entwickelte Golgi-Apparat vorwiegend im apikalen bzw. medianen Cytoplasma lokalisiert sind, wird die basale Region der Zellen in der Hauptsache von einzelnen Kanälen eines rauhen, endoplasmatischen Retikulums durchzogen. Eine dichtgepackte, lamellenartige Anordnung dieser Kanäle zu einem organisierten Ergastoplasma wie im Falle der Becherzellen (vg1. Abb. 3) liegt jedoch nicht vor. Die Zellen mit apikalen Sekretgrana enthalten einzelne, verstreut liegende Mitochondrien, ohne erkennbare Vorzugslage.

Wie bereits früher beschrieben (KOMNICK 1965b), werden gelegentlich Zellen mit apikalen Sekretgrana gefunden, deren Apex in Form eines etwa 2 bis $4 \mu$ breiten Sekretkanälchens ins Zellinnere eingestïlpt ist. Wie auf Längsschnitten deutlich wird, reichen diese Einstülpungen häufig bis unmittelbar an den Zellkern heran (Abb. 11a). Sie sind kranzartig von 1 bis 2 Lagen Sekretgrana umgeben und zeigen den gleichen Mikrovillibesatz wie die Zelloberfläche. Querschnitte lassen erkennen, daß es sich um röhrenförmige Einstülpungen des Zellapex handelt (Abb. 11b), vergleichbar den Sekretkanälchen in den Belegzellen der Fundusdrüsen (HELANDER 1962, KOMNICK 1963b, SEDAR 1964). Ihre funktionelle Bedeutung dürfte in einer Vergrößerung der sekretorischen Zelloberfläche zu sehen sein.

$\mathrm{Da}$ die Becherzellen und die Zellen mit apikalen Sekretgrana trotz der großen Unterschiede in der Zellform und der Art der Sekretspeicherung hinsichtlich der Cytoplasmaorganisation gemeinsame Grundzüge aufweisen, wurde mit Hilfe histochemischer Methoden versucht, Aufschlüsse über die Natur der von diesen Zellen produzierten Substanzen zu erlangen. Dabei konnte festgestellt werden, daß die Sekrettropfen in beiden Zelltypen eine positive Reaktion sowohl mit dem Perjodsäure-Schiff-Reagenz nach McManus wie auch mit Alcianblau und kolloidalem Eisen nach Hale erbrachten (vgl. Abb. 1a bis c). Sie enthalten demnach in beiden Fällen einen hohen Anteil an Glycoproteiden und sauren Mucopolysacchariden. Die Vermutung, daß es sich bei den Zellen mit apikalen Grana um Entwicklungstadien von Becherzellen handelt, scheint uns wegen der großen morphologischen Unterschiede und wegen des Fehlens weiterer Übergangsstadien nicht gerechtfertigt. Morphologisch wird in beiden Zelltypen das 


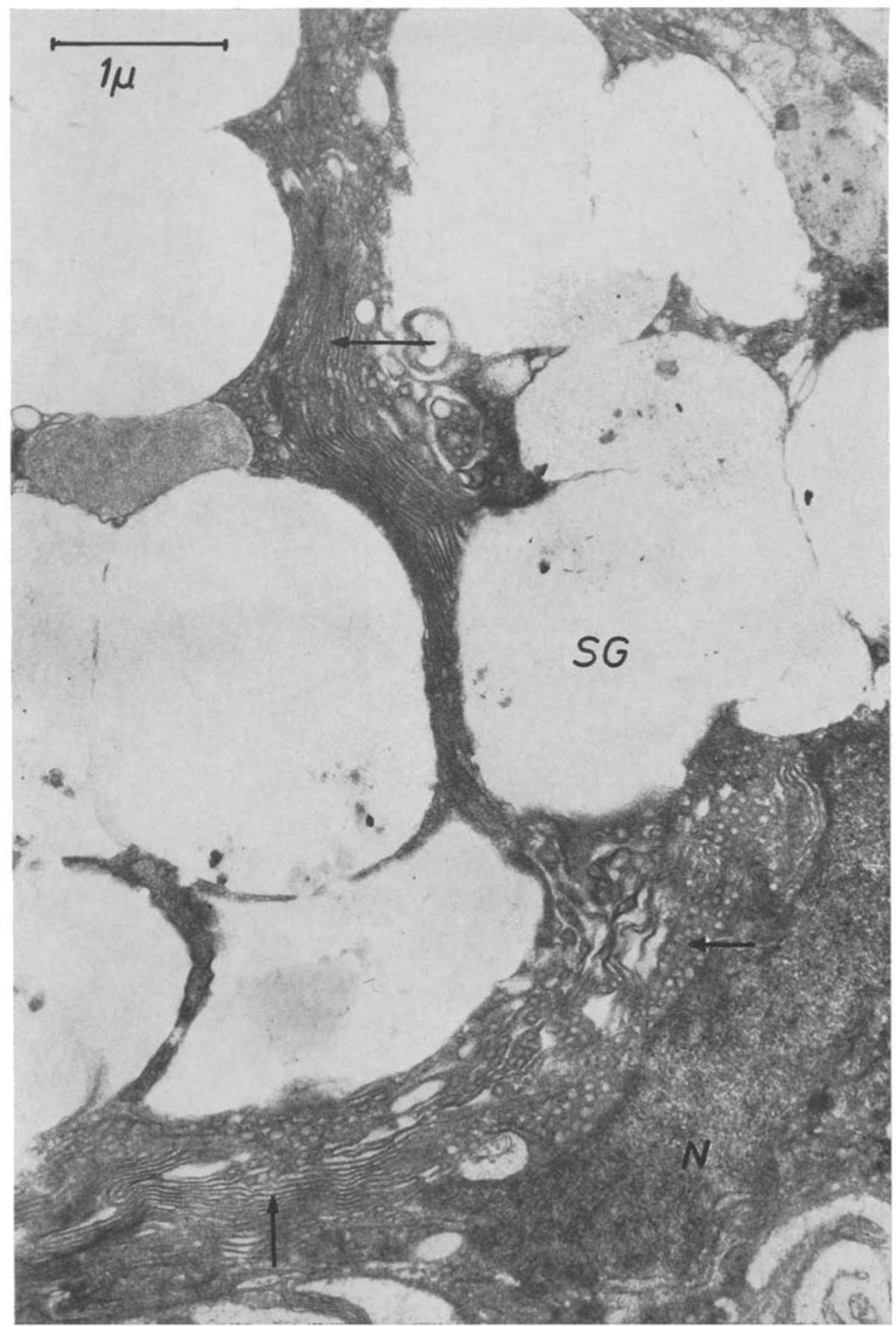

Abb. 4: Raja batis; Ausschnittvergrößerung aus dem Golgi-Apparat einer Becherzelle des Ausführganges der Rectaldrüse mit gestapelten Golgi-Zisternen (Pfeile) und Vesikelfeldern (Pfeil). $\mathrm{N}=$ Nucleus; $\mathrm{SG}=$ Schleimgrana. $\left(\mathrm{O}_{5} \mathrm{O}_{4} / \mathrm{K}_{2} \mathrm{Cr}_{2} \mathrm{O}_{7}\right.$, Fixierung $\mathrm{Nr}$. 5, Vestopaleinbettung. $23000: 1)$ 


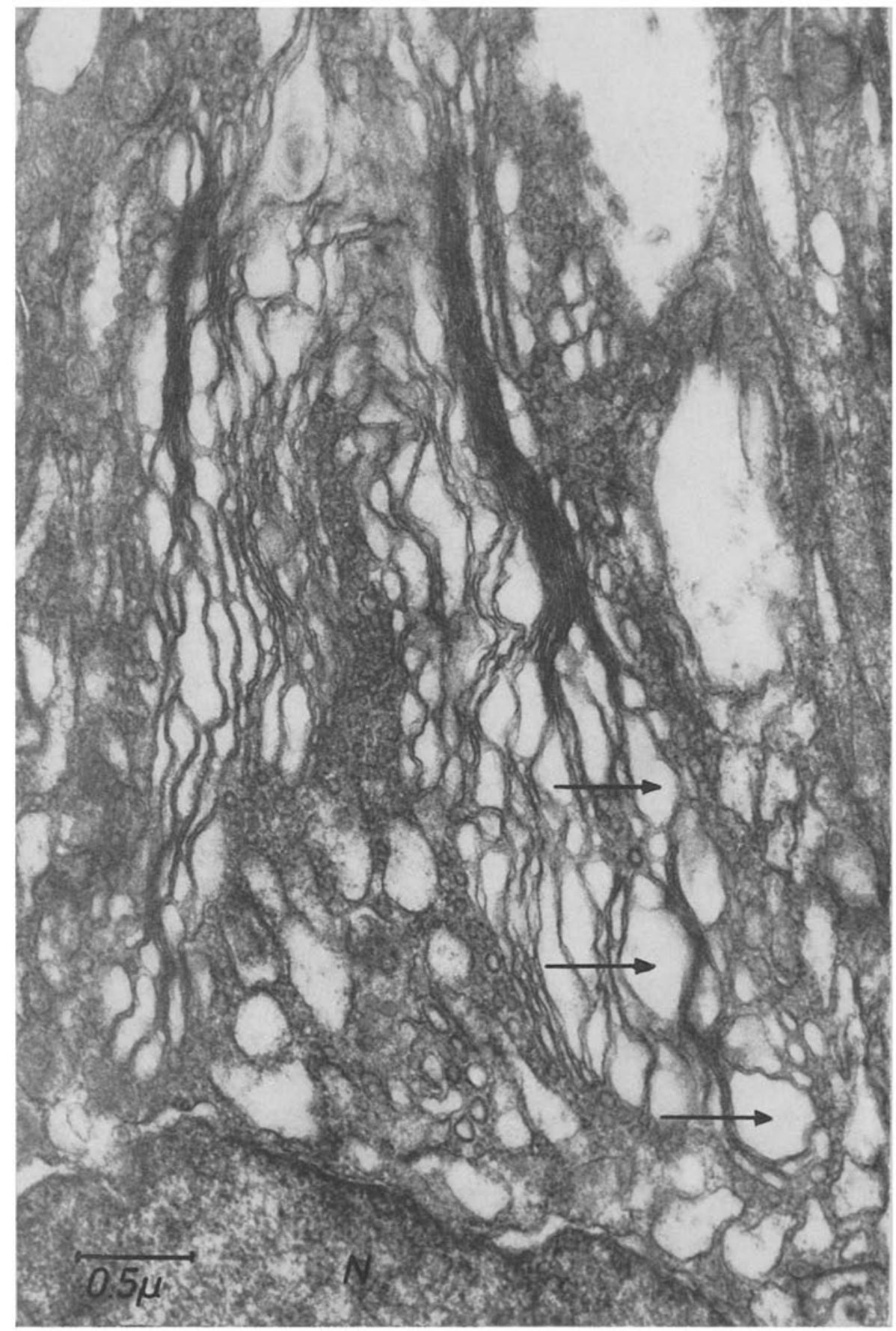

Abb. 5: Raja batis; sekretorisch stark aktive Dictyosomen einer Becherzelle mit peripheren, vakuolenförmigen Auftreibungen der Golgi-Zisternen (Pfeile). $\mathrm{N}=$ Nucleus $\left(\mathrm{OsO}_{4} / \mathrm{K}_{2} \mathrm{Cr}_{2} \mathrm{O}_{7}\right.$, Fixierung Nr. 5, Vestopaleinbettung. 30 600:1) 


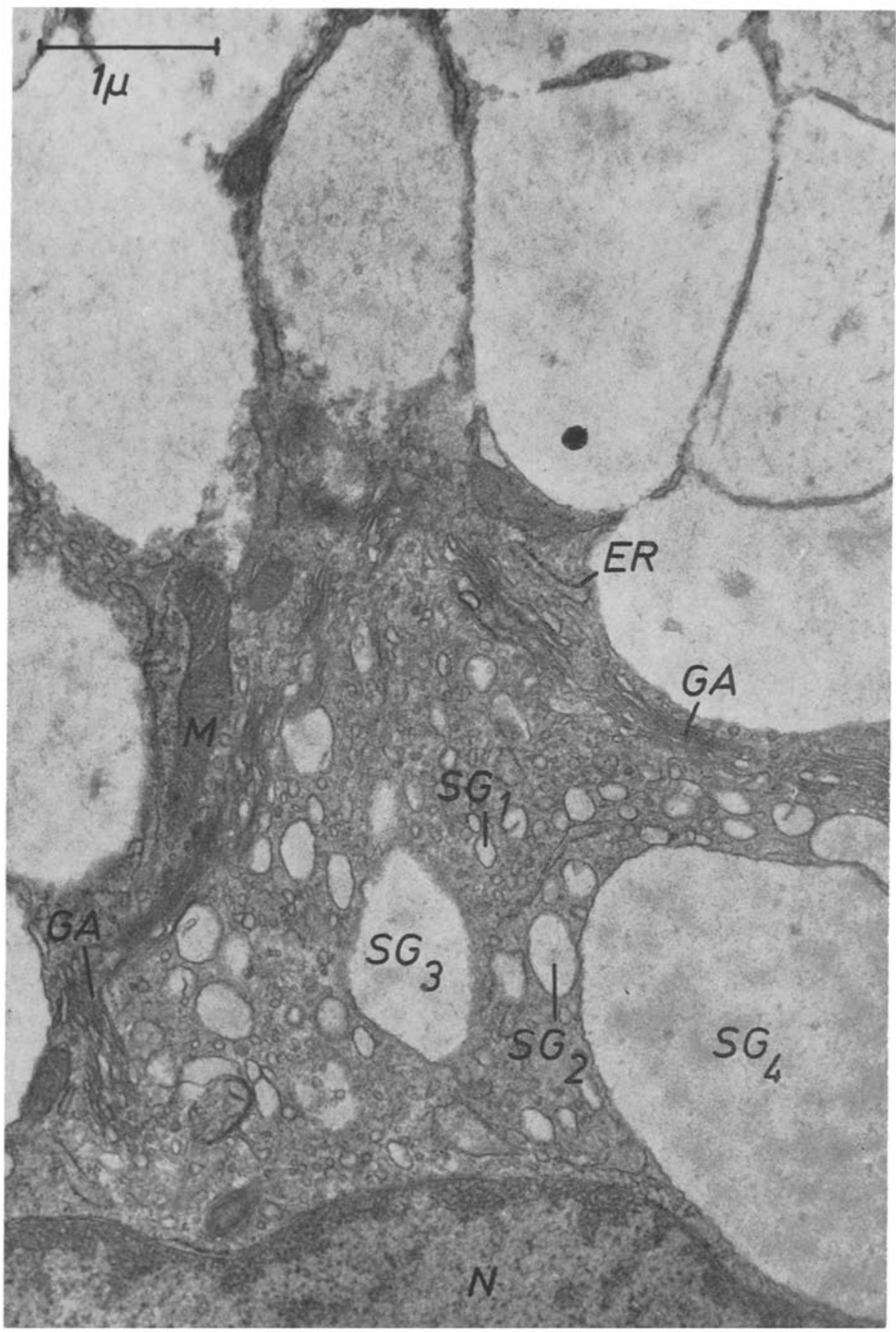

Abb. 6: Galeorbinus galeus; Teile des Golgi-Apparates (GA) der supranucleären Cytoplasmaregion einer jungen Becherzelle. Das Alter der Schleimgrana ist deutlich an ihrer Größe erkennbar $\left(\mathrm{SG}_{1}-\mathrm{SG}_{4}\right) . \mathrm{N}=$ Nucleus; $\mathrm{ER}=$ rauhes, endoplasmatisches Retikulum; $\mathrm{M}=$ Mitochondrium. (Glutaraldehyd/OsO $\mathrm{O}_{4}$, Fixierung Nr. 8, Vestopaleinbettung. 24 300:1) 


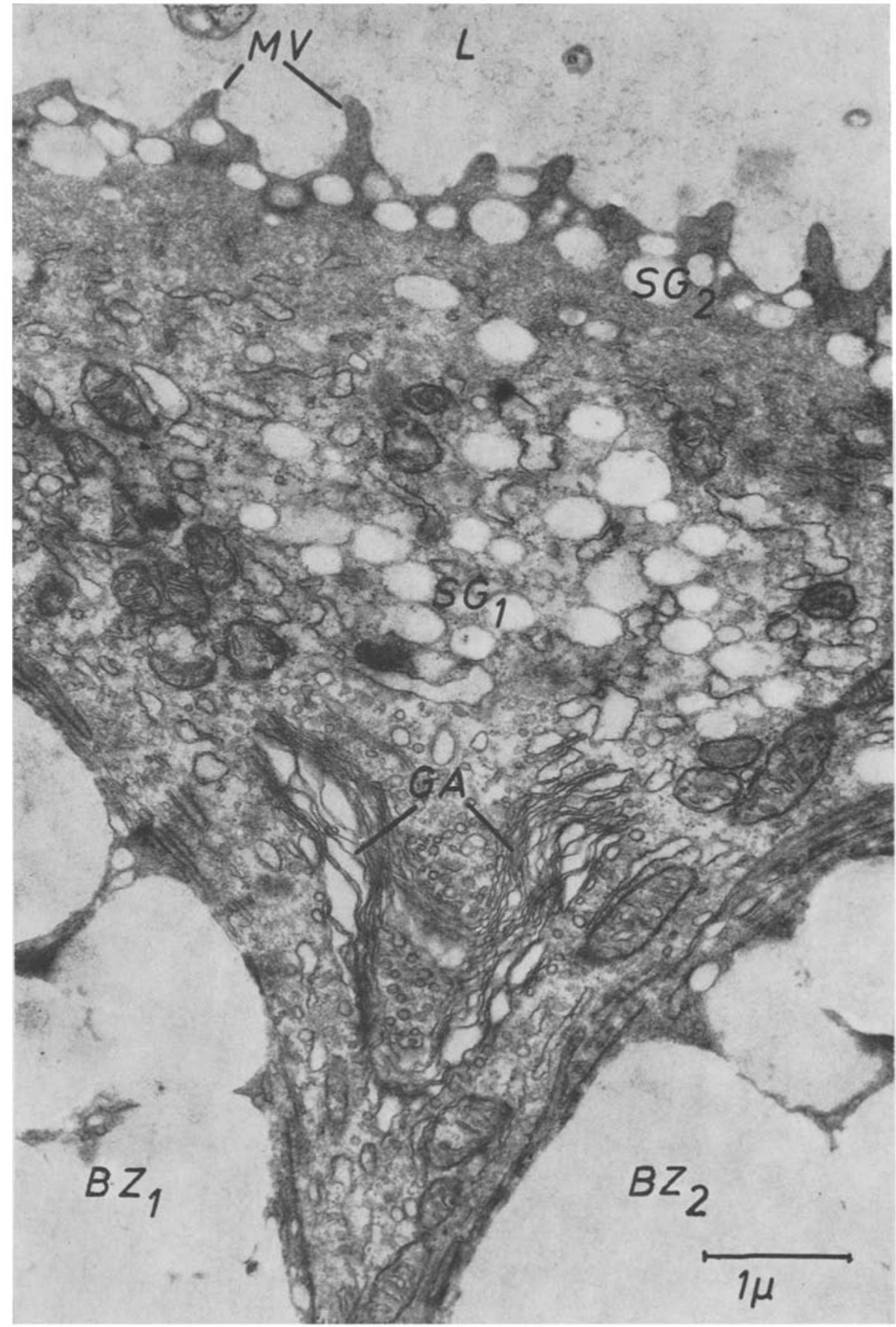

Abb. 7: Raja batis; sekretorische Zelle (hantelförmiger Typ) aus dem zentralen Sammelkanalepithel der Rectaldrüse. Die Schleimgrana liegen gehäuft oberhalb des Golgi-Apparates ( $\mathrm{SG}_{1}$ ) sowie reihenförmig angeordnet unter dem Zellapex (SG2). $\mathrm{BZ}_{1}$ und $\mathrm{BZ}_{2}=$ benachbarte Becherzellen; $\mathrm{GA}=$ einzelne Dictyosomen des Golgi-Apparates; $\mathrm{MV}=$ Mikrovilli; $\mathrm{L}=$ Lumen des Zentralkanals. $\left(\mathrm{O}_{5} \mathrm{O}_{4} / \mathrm{K}_{2} \mathrm{Cr}_{2} \mathrm{O}_{7}\right.$, Fixierung Nr. 5, Vestopaleinbettung, Bleicitratkontrastierung. $20000: 1$ ) 


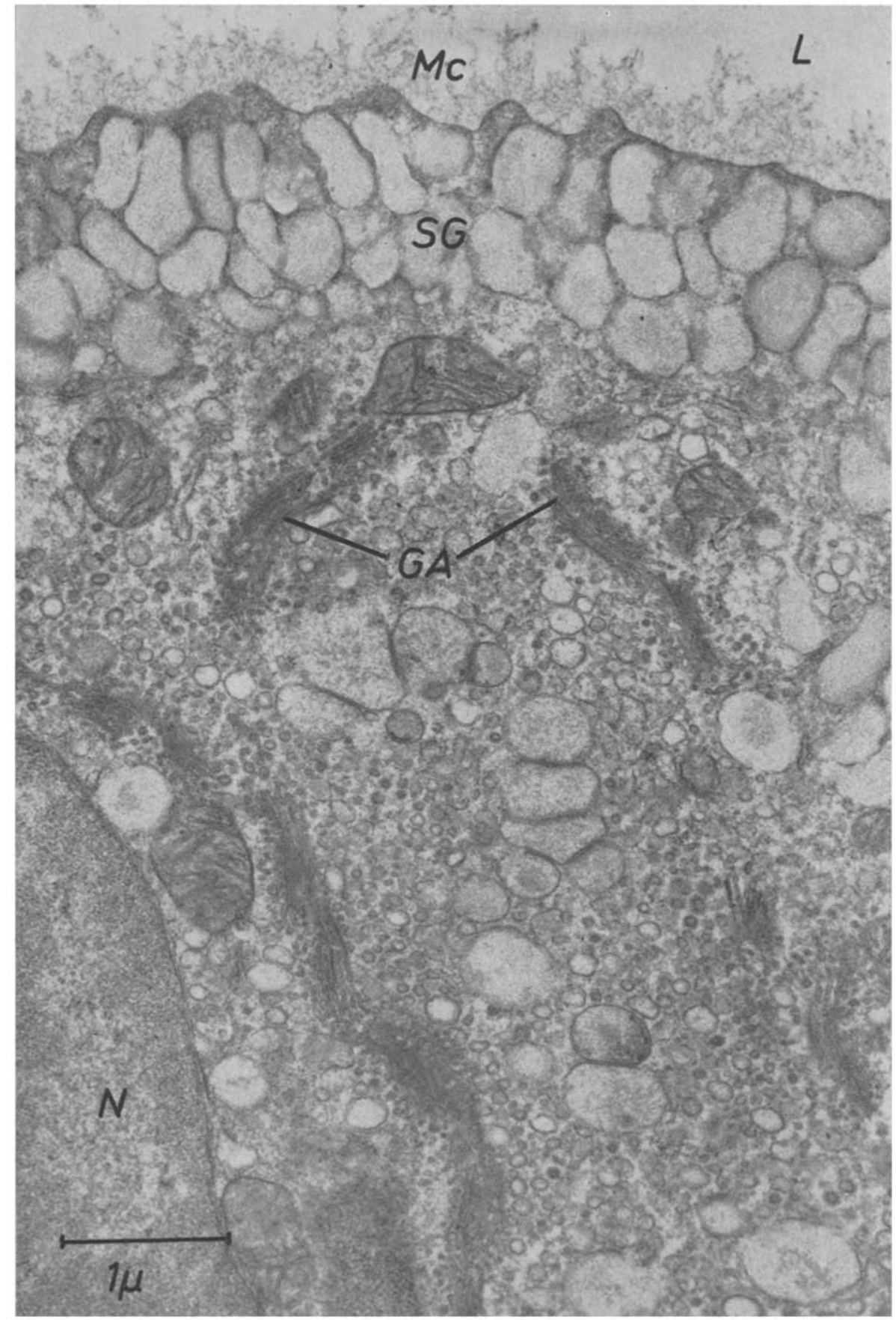

Abb. 8: Galeorbinus galeus; sekretorische Zelle mit apikalen Sekretgrana (SG) aus dem zentralen Sammelkanal der Rectaldrüse (Prismatischer Zelltyp). Der Zellapex ist von einer fädigen Mucoidschicht (Mc) überzogen. Zahlreiche Dictyosomen (GA) durchziehen dicht aufeinanderfolgend das an kleinen Vesikeln reiche Cytoplasma. $\mathrm{L}=$ Lumen des Sammelkanals, $\mathrm{N}=$ Nucleus. (OsO $\mathrm{K}_{2} \mathrm{Cr}_{2} \mathrm{O}_{7}$, Fixierung Nr. 5, Vestopaleinbettung. 22 400:1) 
erste Sekret im Golgi-Feld sichtbar. Mit Methoden, die in der letzten Zeit in der Elektronenmikroskopie zur Darstellung von sauren Mucopolysacchariden benutzt wurden, haben wir versucht, die Herkunft des Sekretes weiter zurückzuverfolgen. Da das von Wetzel, Wetzel \& Spicer (1966) empfohlene $\mathrm{FeCl}_{3}$ keine befriedigenden Ergebnisse erbrachte, wurde die auch aus der Lichtmikroskopie bekannte und ebenfalls von den vorhin genannten Autoren geprüfte Methode mit kolloidalem Eisen nach HaLE (BARKA \& ANDERSON 1963) mit und ohne Visualisierung des Eisens zur elektronenmikroskopischen Darstellung der sauren Mucopolysaccharide verwendet. Die Schwierigkeit bei dieser Methode liegt vor allem in dem Nachweis intrazellulärer Schleimsubstanzen, da die etwa 50 A großen Eisenpartikel nur präparativ stark geschädigte Zell- und Cytoplasmamembranen passieren können. Ein weiterer Nachteil stellt die durch das saure Milieu bedingte schlechte Strukturerhaltung der meisten Zellorganellen dar. Trotzdem gelang es in einigen Fällen mit Hilfe kolloidalen Eisens, die sauren Mucopolysaccharide in den Becherzellen (Abb. 12a) sowie in den Zellen mit apikalen Sekretgrana (Abb. 12b) extra- sowie intrazellulär näher zu lokalisieren. Das kolloidale Eisen drang dabei bis in die in unmittelbarer Nähe des Golgi-Komplexes gelegenen Sekretvesikel ein. Ein Nachweis der Substanzen im Golgi-Apparat selbst war jedoch auf Grund der bereits erwähnten und durch die Methode bedingten schlechten Strukturerhaltung nicht möglich.

(c) Fla schenzelle n wurden von BuLger (1965) bereits beim Dornhai beschrieben und konnten von uns in geringer Anzahl auch beim Grundhai, Katzenhai und Glattrochen gefunden werden. Sie stehen immer einzeln, sind lichtmikroskopisch schwierig zu identifizieren und können noch am ehesten an ihrem lang ausgezogenen und ins Sammelkanallumen hineinragenden Zellapex erkannt werden (Abb. 13). Thre sublichtmikroskopische Morphologie unterscheidet sich in wesentlichen Strukturmerkmalen deutlich von den bis jetzt beschriebenen schleimproduzierenden Zelltypen: Dictyosomen werden nur vereinzelt gefunden: sie sind klein und unaufallig und bestehen in der Regel nur aus wenigen Zisternen. Anteile eines rauhen oder glatten endoplasmatischen Retikulums sind ebenfalls selten. Auffällig ist der verhältnismäßig große und die gesamte Zellbasis ausfüllende Kern. Das supranukleäre Cytoplasma wird in erster Linie durch vereinzelte Mitochondrien sowie durch zahlreiche Vesikel von 0,1 bis $0,2 \mu$ Durchmesser geprägt. Die Vesikel, deren Zahl zum Zellapex hin abzunehmen scheint, enthalten teils einen dichten Inhalt, teils erscheinen sie elektronenoptisch leer. Am Grunde der wenigen mikrovilliartigen Protuberanzen des Zellapex können häufig reihenförmig angeordnete Vesikel angetroffen werden (Abb. 13, Pfeil), die auf eine endocytotische Aktivität der Zellen schließen lassen. In Ubereinstimmung hiermit beinhaltet das Cytoplasma in der Regel auch lysosomenartige Strukturen, deren Auftreten heute ebenfalls mit endocy totischen Prozessen in Verbindung gebracht wird.

(d) Mitochondrienreiche Zellen konnten nur im Sammelkanalepithel der Rectaldrüse von Katzenhaien nachgewiesen werden. Sie bilden hier zahlenmäßig den weitaus größten Teil der luminalen Schicht und gleichen den Zellen der Drüsentubuli, in deren einschichtiges Epithel sie an den seitlichen Einmündungen lülkkenlos übergehen. Die mitochondrienreichen Zellen bilden über weite Strecken die einzige epitheliale Begrenzung des Kanallumens (Abb. 14 und 15). Dort, wo sie von Becherzellen und Zellen mit apikalen Sekretgrana abgelöst werden, ist das Sammel- 


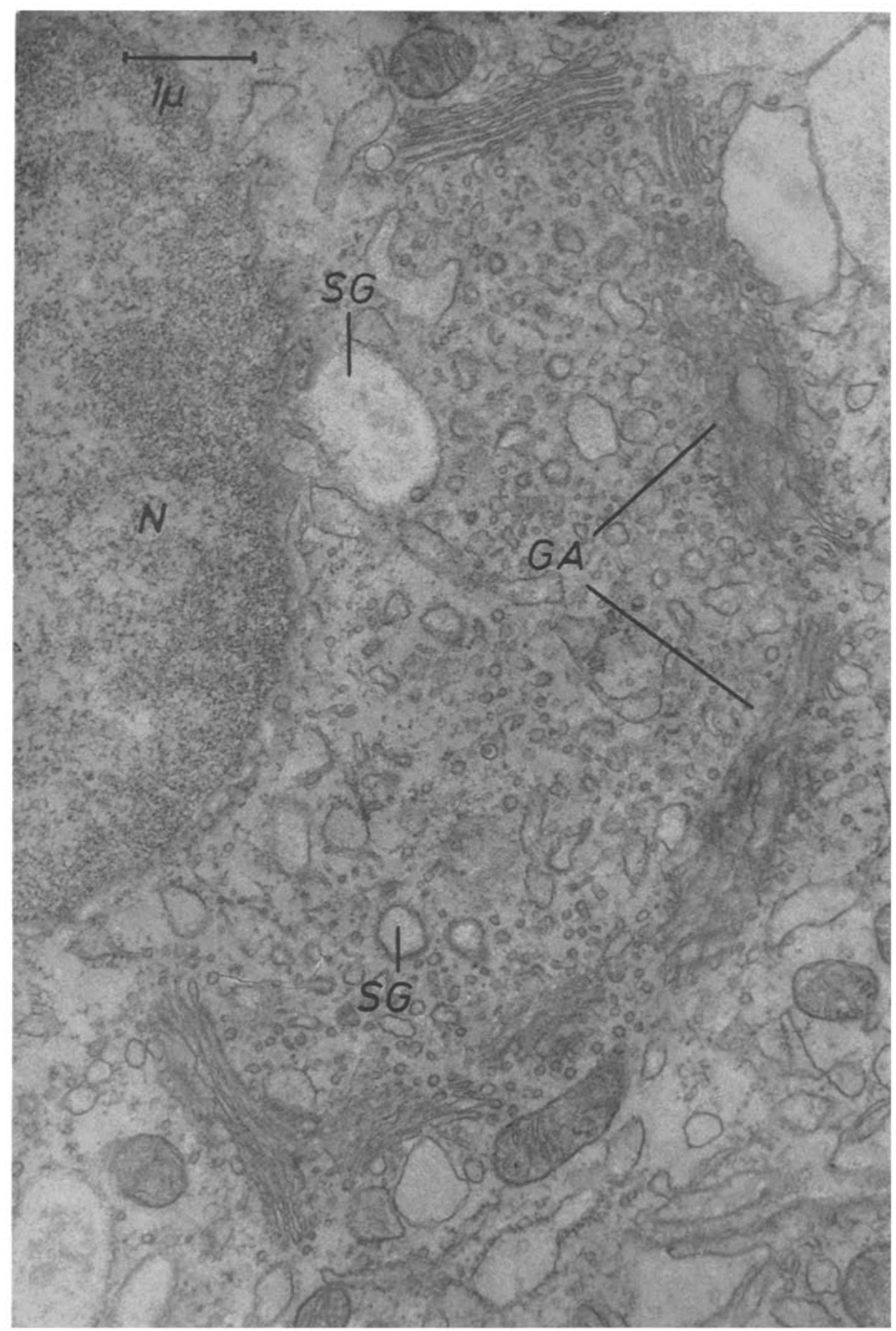

Abb. 9: Galeorbinus galeus; Ausschnittvergrößerung des perinudeären Cytoplasmas einer sekretorischen Zelle mit apikalen Sekretgana aus dem Sammelkanalepithel (prismatischer Zelltyp). Zahlreiche Dictyosomen (GA) umschließen den Kern (N) hufeisenförmig. Das vom Golgi-Apparat umschlossene Cytoplasma ist reich an kleinen Vesikeln und jungen Schleimgrana (SG). (OsO $/ \mathrm{K}_{2} \mathrm{Cr}_{2} \mathrm{O}_{7}$, Fixierung $\mathrm{Nr} .5$, Vestopaleinbettung. $\left.24300: 1\right)$ 


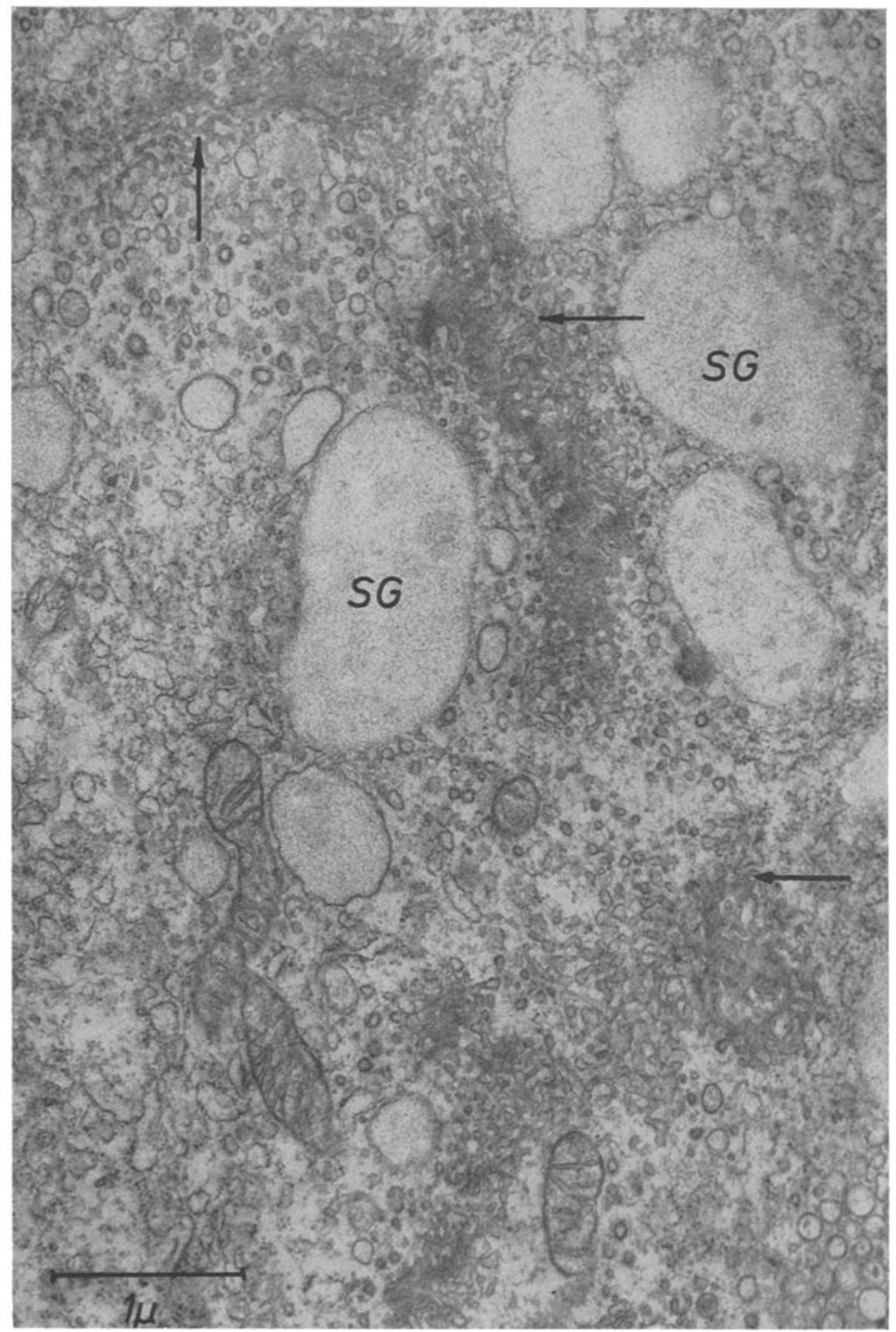

Abb. 10: Galeorbinus galews; Golgi-Komplex einer sekretorischen Zelle mit apikalen Sekretgrana (prismatischer Zelltyp) aus dem Sammelkanalepithel der Rectaldrüse. Flachschnitte durch die Dictyosomen zeigen die besondere Struktur dieses Zellorganells. Die Golgi-Zisternen besitzen zahlreiche Fenster (Pfeile); $\mathrm{SG}=$ Schleimgrana. $\left(\mathrm{O}_{5} \mathrm{O}_{4} / \mathrm{K}_{2} \mathrm{Cr}_{2} \mathrm{O}_{7}\right.$, Fixierung $\mathrm{Nr}$. 5, Vestopaleinbettung. 25000:1) 

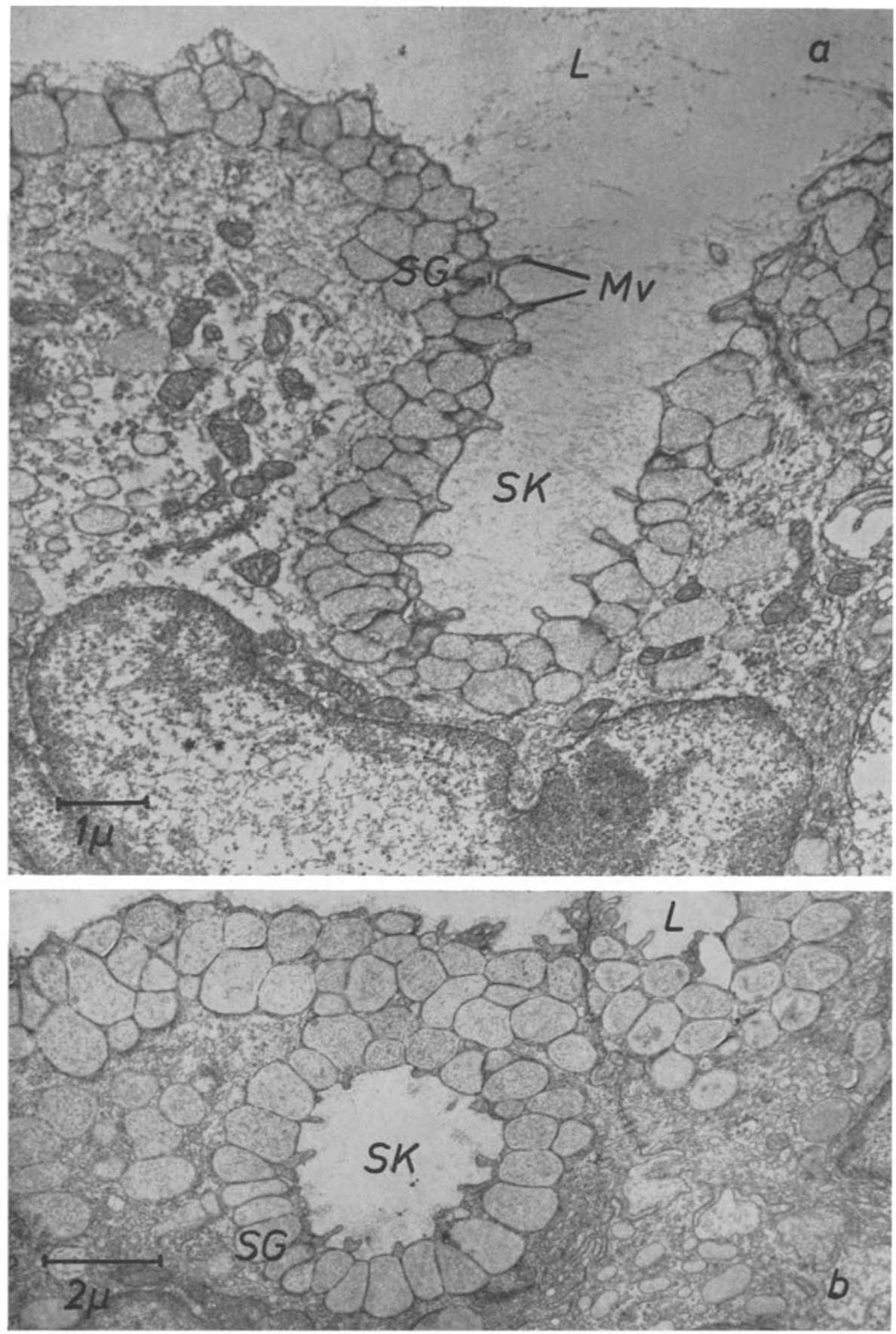

Abb. 11: Galeorbinus galeus; sekretorische Zelle mit apikalen Sekretgrana (prismatischer Zelltyp) aus dem zentralen Sammelkanal der Rectaldrüse mit innerzelligem, im Längs- (a) und Querschnitt $(b)$ getroffenem Sekretkanälchen (SK). Die Sekretkanälchen sind kranzartig von Schleimgrana (SG) umgeben. $\mathrm{L}=$ Lumen des Sammelkanals; $\mathrm{Mv}=$ Mikrovilli. (OsO 4 $\mathrm{K}_{2} \mathrm{Cr}_{2} \mathrm{O}$, Fixierung Nr. 5, Vestopaleinbettung. $\left.a=11000: 1, b=7250: 1\right)$ 

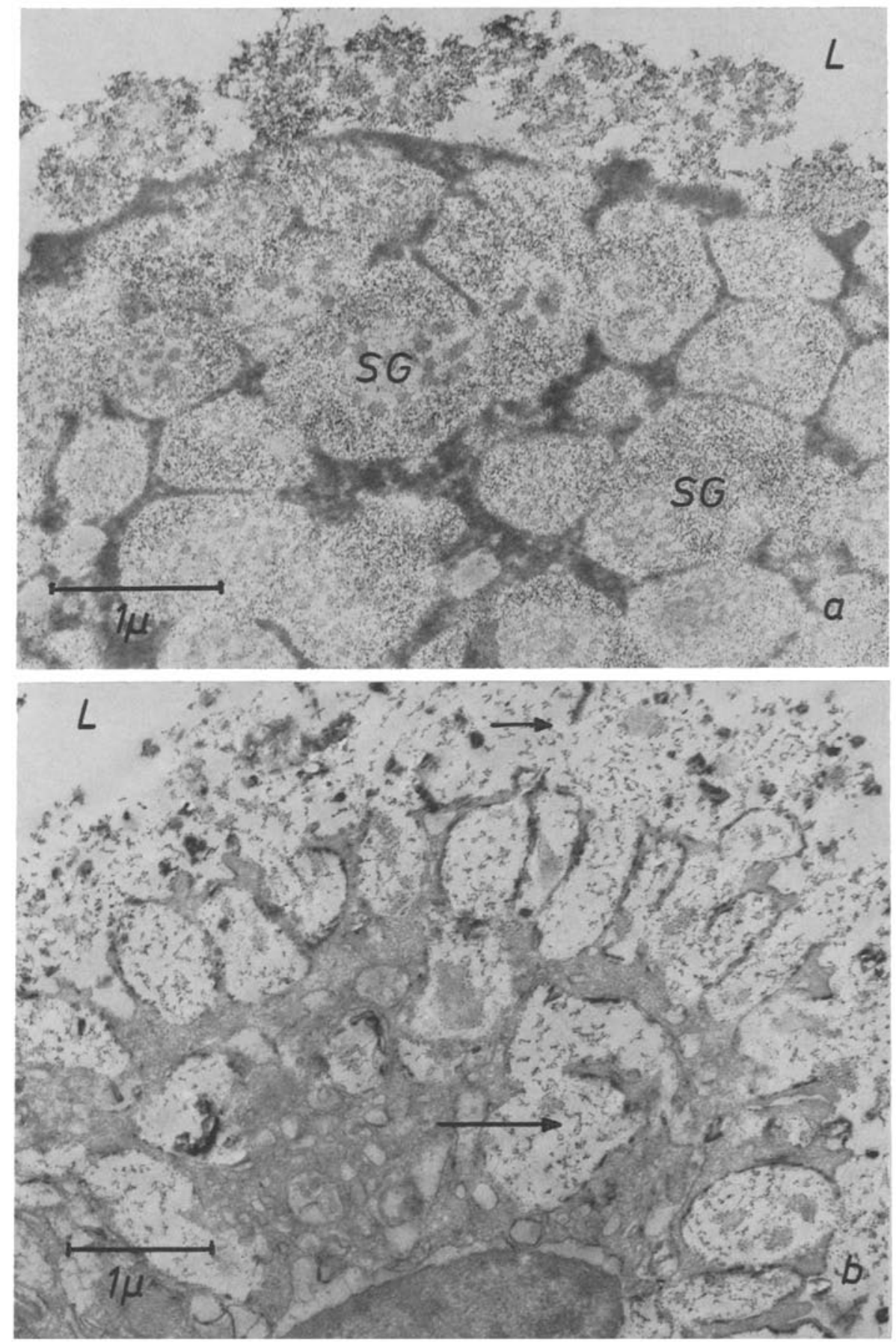

Abb. 12: Galeorbinus galeus; (a) Junge Becherzelle aus dem zentralen Sammelkanal der Rectaldrüse. Die Sekretgrana (SG) sowie der extrazelluläre Schleim (Glycocalyx) zeigen positive Hale-Reaktion. (Glutaraldehyd-OsO $\mathrm{O}_{4}$, Fixierung Nr. 8, Hale-Reaktion, Vestopaleinbettung. 22 400:1). (b) Zelle mit apikalen Sekretgrana (prismatischer Zelltyp) aus dem zentralen Sammelkanal der Rectaldrüse. Der intra- (Pfeil) und extrazelluläre (Pfeil) Schleim ist deutlich mit Eisen tingiert, Visualisierung des Eisens mit Kaliumferrocyanid. (Fixierung und Einbettung siehe Abbildung 12a. 19200:1) 


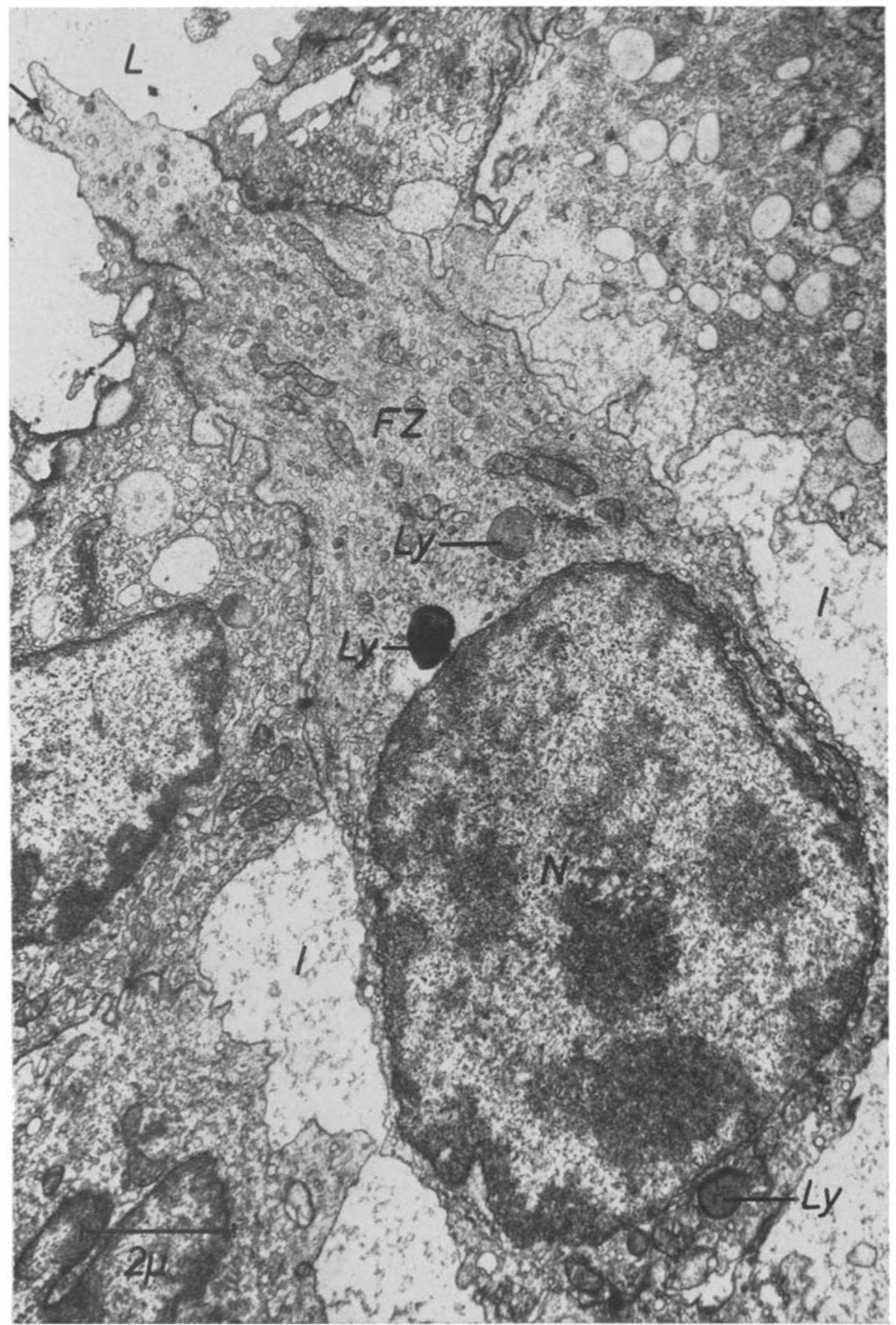

Abb. 13: Galeorbinus galeus; Flaschenzelle (FZ) aus dem zentralen Sammelkanalepithel der Rectaldrüse; der Zellapex läßt Anzeichen einer endocytotischen Alktivität erkennen (Pfeil). $\mathrm{L}=$ Lumen des Sammelkanals; $\mathrm{Ly}=$ Lysosomen-artige Strukturen; $\mathrm{N}=$ Nucleus; $\mathrm{I}=$ erweiterte Interzellularen mit flockigem Inhalt. $\left(\mathrm{OsO}_{4} / \mathrm{K}_{2} \mathrm{Cr}_{2} \mathrm{O}_{7}\right.$, Fixierung Nr. 5, Vestopaleinbettung. $10000: 1)$ 


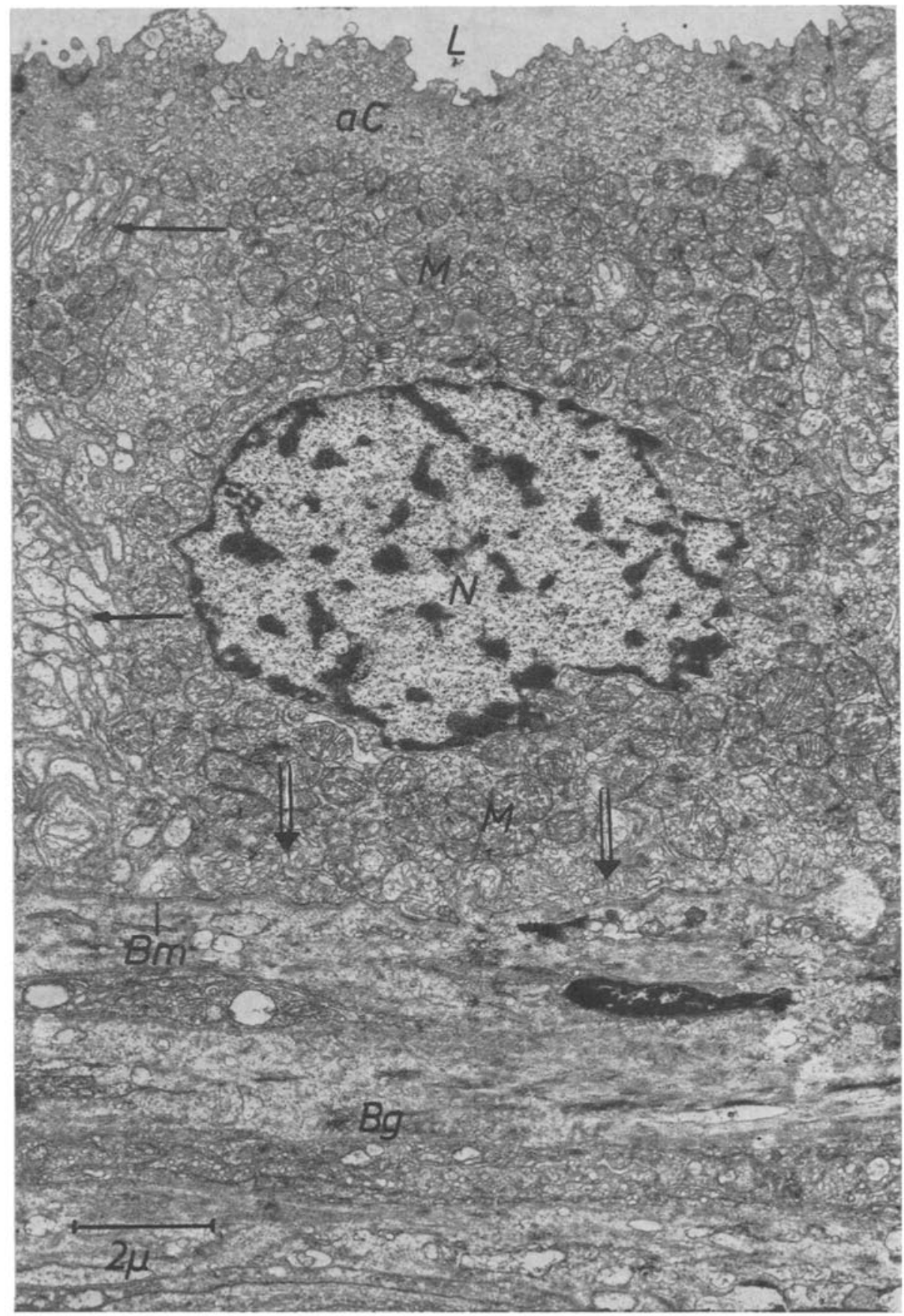

Abb. 14: Scylliorbinus canicula; Längsschnitt durch den proximalen Teil der Rectaldrüse. Die dargestellte Zelle aus dem einschichtigen zentralen Sammelkanalepithel zeichnet sich durch ihren Reichtum an Mitochondrien (M) sowie durch laterale Verzahnungen (Pfeile) und ein basales Labyrinth (Doppelpfeile) aus. aC $=$ apikales Cytoplasma; $\mathrm{L}=$ Lumen des zentralen Sammelkanals; $\mathrm{N}=$ Nucleus; $\mathrm{BG}=$ Bindegewebszellen; $\mathrm{Bm}=$ Basalmembran. (Glutaraldehyd/ $\mathrm{Os}_{4} \mathrm{O}_{4}$, Fixierung Nr. 6, Vestopaleinbettung, Bleicitratkontrastierung, 9000:1) 


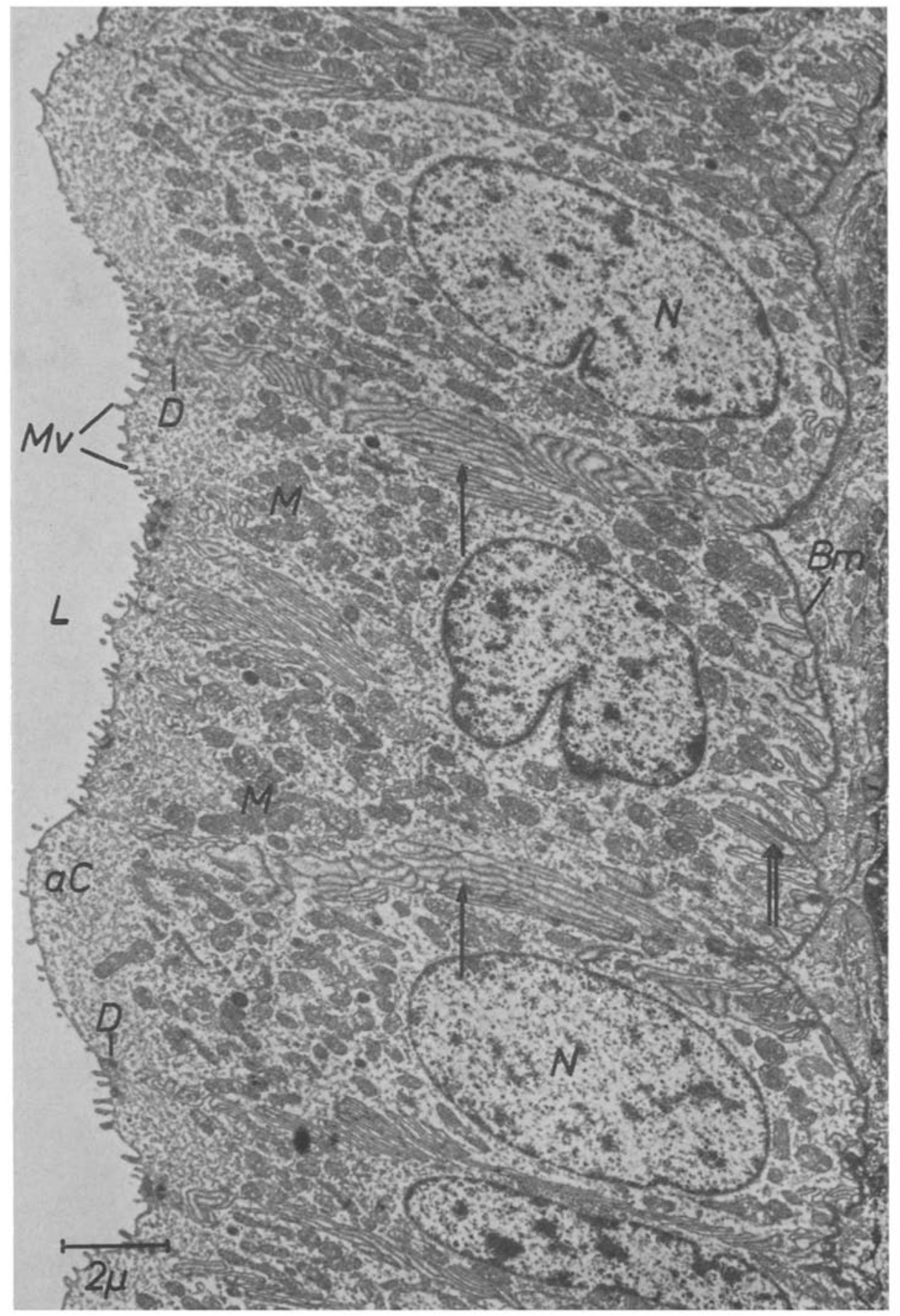

Abb. 15: Scylliorbinus canicula; Längsschnitt durch das einschichtige Epithel des zentralen Sammelkanals der Rectaldrüse. Die mitochondrienreichen Zellen sind lateral verzahnt (Pfeile) und besitzen ein basales Labyrinth (Doppelpfeil). $\mathrm{Mv}=$ Mikrovilli; $\mathrm{D}=$ Schlußleisten (übrige Beschriftung vgl. Abb. 13). (Glutaraldehyd/OsO4, Fixierung Nr. 6, Methacrylateinbettung, Uranylacetat-Bleicitratkontrastierung. 7000:1) 


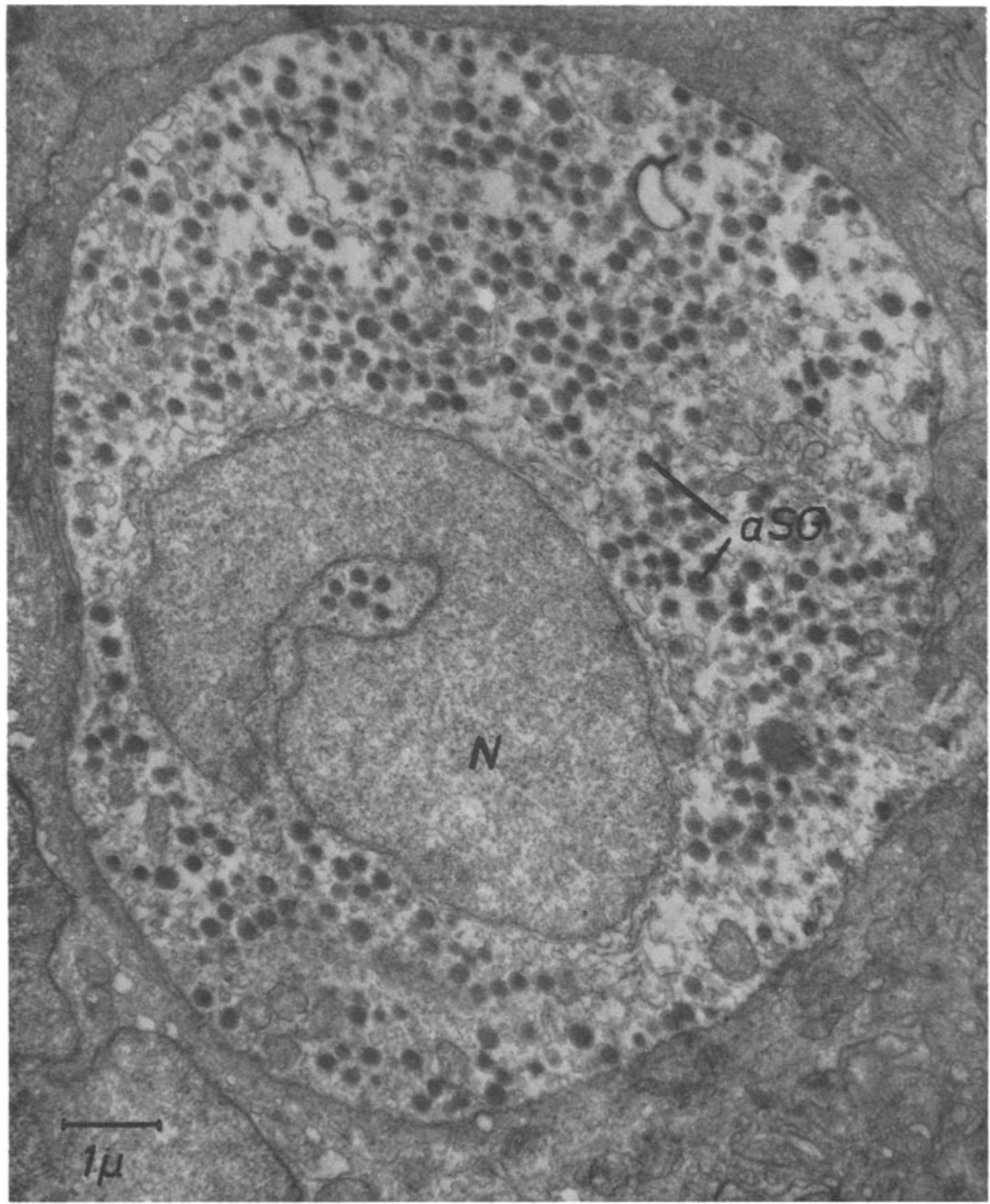

Abb. 16: Raja batis; wahrscheinlich argentaffine Zelle aus der basalen Epithelregion des Zentralkanals der Rectaldrüse. $a S G=$ Sekretgrana; $\mathrm{N}=$ Nucleus. $\left(\mathrm{O}_{5} \mathrm{O}_{4} / \mathrm{K}_{2} \mathrm{Cr}_{2} \mathrm{O}_{7}\right.$, Fixierung Nr. 5, Vestopaleinbettung. $11000: 1)$

kanalepithel in der Regel zwei- bis dreischichtig. Morphologisch lassen sich diese Zellen durch ihren großen Mitochondrienreichtum charakterisieren (Abb. 14). Auffallend ist weiterhin eine Mitochondrien-freie apikale Cytoplasmaregion, deren dichtes Grundplasma vereinzelt kleine Vakuolen beinhaltet. Als zweites Differenzierungsmerkmal von Bedeutung muß die innige laterale Verzahnung der Zellen genannt werden (Abb. 
15), die eine Vergrößerung der Zellmembranoberfläche und die Ausbildung eines labyrinthartigen Interzellularraumsystems zur Folge hat.

Die mitochondrienreichen Zellen, die auch im Sammelkanalepithel der Rectaldrüse des Dornhaies vorkommen (BULGER 1965), entsprechen in ihrem Feinbau den Tubulusepithelzellen der Rectaldrüse (vgl. Komnick \& WohlFarth-BotTERManN 1966).

(2) Die bas a le E pit hels e it e setzt sich in der Regel aus mehreren Zellagen zusammen. Die licht- und elektronenmikroskopisch wenig differenzierten Zellen bilden einen verzahnten Verband mit deutlichen Interzellularspalten, die - wie auch in der luminalen Epithelschicht - stellenweise erheblich erweitert sind und dann einen flockigen Inhalt erkennen lassen (Abb. 13). Die Struktur des Cytoplasmas dieser Zellen zeigt keine besonderen Differenzierungsmerkmale und entspricht auch bei den von uns untersuchten Knorpelfischarten im wesentlichen den bereits von BULGER (1965) beim Dornhai beschriebenen Verhältnissen: Neben Mitochondrien können vor allem Anteile eines sowohl glatten wie auch rauhen endoplasmatischen Retikulums sowie vereinzelte Dictyosomen gefunden werden. In unmittelbarer Nähe der meist polymorph gestalteten Zellkerne werden häufig große Lipoidtropfen angetroffen, die auch schon von BuLGEK (1965) beobachtet wurden. An Orten stark erweiterter Interzellularspalten liegen oft andersartige, wahrscheinlich dem Blut entstammende Zellen vom Lymphocyten- und Granulocyten-Typ sowie degenerierende Zellen in verschiedenen Stadien der Autolyse. Ferner fallen granulierte Einzelzellen auf, die strukturell eine große Ahnlichkeit zu neutrophilen Granulocyten einerseits (ITO \& WINCHEsTER 1963) und zu den enterochromaffinen Zellen (HELANDER 1962) andererseits aufweisen (Abb. 16). Da die Rectaldrüse als Ausstülpung der Darmwand entstanden ist, könnte es sich hierbei um einen den enterochromaffinen Zellen entsprechenden Zelltyp handeln.

\section{DISKUSSION}

Der Rectaldrüse von Knorpelfischen muß auf Grund der bis jetzt vorliegenden Befunde sowohl exkretoris he (Burger \& Hess 1960, Burger 1962, Butger 1963, KomNick 1965a und b) als auch sek retoris che Funktion (Bulger 1965, KомNick 1965b) zugesprochen werden, Entsprechend dieser zweifachen funktionellen Bedeutung lassen sich zwei morphologisch voneinander trennbare Anteile des Organs unterscheiden, die für die Exkretion konzentrierter Kochsalzlösungen einerseits sowie für die Sekretion von schleimartigen Substanzen andererseits verantwortlich sind. Der exkretorische Teil besteht aus einem von zahlreichen Schläuchen gebildeten Drüsenparenchym, dessen Epithel sich fast ausschließlich aus transportierenden Zellen zusammensetzt. Die Morphologie dieser Zellen wurde zuletzt von Komsick \& WoHLFARTH-BOTTERMANN (1966) beschrieben: sie sind durch ihren Reichtum an Mitochondrien sowie durch ihre polymorphe Gestalt gekennzeichnet. Durch laterale grobe und feine Verzahnungen entsteht ein labyrinthartiges Interzellularensystem und eine stark vergrößerte Zelloberfläche. Die Bedeutung dieser Strukturmerkmale wurde kürzlich von KoMNICK (1968) summarisch dargestellt und im Zusammenhang mit den wichtigsten bisher vorliegenden Ergebnissen auch anderer Autoren ausführlich diskutiert. Beim Katzenhai und auch beim Dornhai erstreckt sich die Transportfunktion offenbar auch 
auf Teile des Sammelkanalephitels, wie das Vorkommen der mitochondrienreichen Zellen zu erkennen gibt.

Vor der Entdeckung der extrarenalen Salzausscheidung bei Knorpelfischen durch die Rectaldrüse wurden jedoch schon andere Funktionen dieses Organs, wie die Ausscheidung von Schleimsubstanzen diskutiert (zusammenfassende Darstellung bei BARRINGTON 1957). Die zwischenzeitlich in Vergessenheit geratenen Vorstellungen gewannen kürzlich durch den elektronenmikroskopischen Nachweis von sekretorischen Zelltypen im Sammelkanalepithel erneut an Aktualität (BuLger 1965, KomNick 1965b), obwohl bereits von früheren Autoren (PIxell 1908, Hoskins 1917) Becherzellen im Zentralkanalepithel beobachtet wurden. Diese Zellen besitzen auch im feinstrukturellen Bereich eine große Ahnlichkeit mit den schleimproduzierenden Becherzellen aus dem Darmtrakt von Wirbeltieren (Sedar 1964, Freeman 1962 und 1966, Neutra \& LEBLOND 1966) und besonders mit den mucösen Drüsenzellen der Glandula sublingualis der Ratte (KuRTz 1964). Die enge Lagebeziehung der wichtigsten und am stärksten differenzierten Cytoplasmastrukturen Ergastoplasma, Golgi-Apparat und Sekretvakuolen deutet in der genannten topografischen Reihenfolge von basal nach apikal auf funktionelle Zusammenhänge hin, auf die von verschiedenen Autoren bei anderen schleimsezernierenden Zellen ebenfalls schon aufmerksam gemacht wurde (FRIEND 1965, Neutra \& Leblond 1966, Berlin 1967). Demnach kommt es während der Sekretionsphase zu einem dauernden, vesikulären Membranfluß von den Lamellen des Ergastoplasmas über den regenerierenden zum sezernierenden Pol des Golgi-Apparates sowie zu einer Bildung der Sekretvakuolen an dieser Stelle. Die Transportfunktion zwischen den beiden Zellkompartimenten Ergastoplasma und Golgi-Apparat wird von zahlreichen etwa 600 bis 900 A großen Vesikeln übernommen, die von FrIEND (1965) als „buds" bezeichnet wurden. Die in den Becherzellen des Sammelkanalepithels gefundenen Vesikel entsprechender Größe könnten eine ähnliche Funktion besitzen. Obschon es nicht das Ziel der vorliegenden Untersuchung sein soll, eine ausführliche Beschreibung der spezielleren Sekretionsmorphologie des vorliegenden Becherzellentyps zu geben, lassen unsere Ergebnisse den Schluß zu, daß prinzipiell hinsichtlich des Bildungsmechanismus der Schleimsubstanzen keine grundlegenden Unterschiede zu den Verhältnissen in ähnlichen Zellen anderer Organe bestehen. Die in zahlreichen Publikationen (Brerling 1962, Florey 1960, Freeman 1962 und 1966, Palay 1958, ShearMAN \& Muir 1960) erarbeiteten Vorstellungen über den Verlauf der Sekretsynthese in Becherzellen generell können daher auch im Falle der Rectaldrüse als wahrscheinlich gelten.

Der zweite am Aufbau des Sammelkanalepithels beteiligte Zelltyp mit sekretorischer Funktion wird von prismatischen bzw. hantel- oder pilzförmigen Zellen mit apikalen Sekretgrana repräsentiert. Das Auftreten von zwei Formvarianten scheint dabei weniger Ausdruck von funktionellen Unterschieden zu sein, wie aus der gleichartigen Morphologie des Cytoplasmas geschlossen werden kann, sondern ist wahrscheinlich Folge einer passiven Deformation durch Nachbarzellen. Der von Becherzellen eingekeilte hantel-oder pilzförmige Typ besitzt lediglich die Möglichkeit, den noch zur Verfügung stehenden Raum auszufüllen, wodurch seine äußere Gestalt determiniert ist. An den Orten fehlender Becherzellen entfallen beim prismatischen Zelltyp auch die lateralen Deformationen. 
Die in beiden Formvarianten übereinstimmende Cytoplasmaorganisation erinnert an die Verhältnisse in Zellen aus der Brunner'schen Drüse von Katze (MoE 1960) und Maus (FrIEND 1965). Der Zellapex trägt einige meist kürzere Mikrovilli und ist von einem 0,5 bis $1,0 \mu$ dicken Glycocalyx (BennetT 1963) überzogen. Das apikale Cytoplasma enthält vorwiegend in der Nähe des in der Regel hufeisenförmig angelegten Golgikomplexes einer Gruppe von Sekretvakuolen, die sich teilweise unmittelbar unterhalb der Zelloberfläche zu einer einfachen oder doppelten Reihe formieren. Die Gesamtzahl der Vakuolen bleibt vergleichsweise jedoch deutlich hinter den Verhältnissen in Becherzellen zurück, wodurch beide Zelltypen leicht unterschieden werden können. Auch ein organisiertes Ergastoplasma fehlt; das Vorkommen dieser Zellstruktur ist auf ein lockeres Netzwerk von Kanälen eines rauhen endoplasmatischen Reticulums beschränkt.

Auf Grund der quantitativen Verteilung der drei häufigsten, am Aufbau der Rectaldrüse beteiligten Zelltypen muß dem Drüsenparenchym vorwiegend exkretorische, dem Sammelkanalepithel sekretorische Funktion zugeschrieben werden. Bereits die Ergebnisse von Komnick \& WoHLfarth-BotTErmanN (1966) sowie von Bulger (1965) ließen jedoch vermuten, daß morphologisch und wahrscheinlich auch funktionell keine klare Trennung zwischen diesen Gewebeanteilen der Rectaldrüse möglich ist. Während die erstgenannten Autoren in den exkretorisch tätigen Zellen des Drüsenepithels eine $z$ war schwache, jedoch zweifellos vorhandene sekretorische Tätigkeit im Sinne einer geringen Schleimproduktion nachweisen konnten, fand Bulger (1965) im Sammelkanalepithel der Rectaldrüse des Dornhaies mitochondrienreiche Zellen mit wahrscheinlich transportierender Funktion. Daß es sich hierbei nicht um eine Ausnahme handelt, zeigen die Ergebnisse der vorliegenden Untersuchung am Beispiel des Katzenhaies.

Die sich hieraus ergebenden Konsequenzen können in der Frage zusammengefaßt werden, ob es sich bei der Rectaldrüse der Knorpelfische um ein Organ mit zwei voneinander unabhängigen Funktionen handelt, oder ob das Vorkommen von Zellen unterschiedlicher funktioneller Bedeutung in einem Organ nicht als Ausdruck einer einzigen physiologischen Leistung gesehen werden muß. Eine befriedigende Beantwortung dieser Frage steht jedoch unmittelbar im Zusammenhang mit der Klärung des Problems, welche Beziehungen $z$ wischen dem Vorhandensein von sauren Mucopolysacchariden einerseits und dem Ionentransport andererseits bestehen (vgl. Bennetr 1963, Philpott 1964).

Es muß daher zunächst auch noch offenbleiben, welche Konsequenzen sich hieraus für die Rectaldrüse ergeben. Die Funktion der sogenannten Flaschenzellen, die von Bulger (1965) auch im Sammelkanalepithel des Dornhaies gefunden wurden, ist unbekannt. Sie gleichen strukturell entsprechenden, in der Harnblase der Kröte gefundenen Zellen. Auch Sirva (1966) beschreibt Flaschenzellen im Dickdarmepithel der Maus. Er diskutiert unter anderem eine mögliche Funktion dieser Zellen als Receptoren für physikalische, chemische, osmotische und $\mathrm{pH}$-abhängige Veränderungen des Dickdarmlumeninhaltes. Es besteht die Vermutung, daß auch im vorliegenden Falle die flaschenförmigen Zellen eine regulierende Funktion im Hinblick auf die Zusammensetzung des Rectaldrüsenexkretes im Sammelkanallumen besitzen und daß über sie die sekretorische und exkretorische Tätigkeit der anderen Zelltypen in einer noch ungeklärten Art 
und Weise gesteuert wird. Als Perzeptionsmechanismus wäre eine Endocytose des luminalen Exkretes sowie eine anschließende intrazelluläre Analyse des Vesikelinhaltes denkbar.

Abschließend muß festgestellt werden, daß sich die Frage nach der physiologischen Bedeutung der Rectaldrüse mit einer exkretorischen Funktion allein nicht befriedigend beantworten läßt. Die Ausscheidung konzentrierter Kochsalzlösungen durch die Zellen des Drüsenparenchyms läuft parallel mit einer Sekretion erheblicher Mengen von Schleimsubstanzen durch die Zellen des Sammelkanalepithels. Es bleibt weiteren Untersuchungen vorbehalten, ob es sich dabei um zwei funktionell unterschiedliche und voneinander trennbare Leistungen des Organs handelt, oder ob die Einzelleistungen aller am Aufbau der Rectaldrüse beteiligten Zelltypen im Rahmen einer einheitlichen Gesamtfunktion des Organs liegen. Ein ursächlicher Zusammenhang zwischen den nachgewiesenen exkretorischen und sekretorischen Systemen würde jedenfalls einen Regulationsmechanismus erfordern, der beide Leistungen miteinander korreliert und aufeinander abstimmt.

\section{ZUSAMMENFASSUNG}

1. Das zentrale Sammelkanalepithel der Rectaldrüse der untersuchten Knorpelfischarten (Scylliorbinus canicula, Galeorbinus galeus und Raja batis) besteht aus 3 bis 6 Schichten: einer superfiziellen sowie mehreren basalen Zellschichten.

2. Die superfizielle Epithels chicht wird normalerweise von insgesamt drei verschiedenen Zelltypen gebildet: (a) Becherzellen, (b) Zellen mit apikalen Sekretgrana und (c) Flaschenzellen. Bei Scylliorbinus canicula ist noch ein vierter Zelltyp, die sog. mitochondrienreichen Zellen vorhanden. Die von diesen Zellen gebildeten Areale des Sammelkanalepithels sind stets einschichtig.

3. Die B e c h e r z e 11 e n besitzen eine große Ahnlichkeit mit den schleimproduzierenden Becherzellen aus dem Darmtrakt von Wirbeltieren. Thre dominierenden Strukturmerkmale sind ein gut entwickeltes Ergastoplasma, ein ausgedehnter Golgi-Apparat sowie eine dichte Füllung des Zellapex mit Schleimgrana.

4. Die Z elle $\mathrm{n} \mathrm{mit} \mathrm{a} \mathrm{pikale} \mathrm{n} \mathrm{Sekretgranabesitzen} \mathrm{entweder} \mathrm{prismatische}$ oder hantelförmige Gestalt. Sie enthalten rauhes endoplasmatisches Retikulum sowie einen gut entwickelten Golgi-Apparat. Die Sekretgrana sind locker im GolgiFeld verteilt und formieren sich unmittelbar unter dem Zellapex zu einer oder mehreren geschlossenen Reihen.

5. Die Flas chen z ell e n sind durch ein Cytoplasma charakterisiert, welches zahlreiche kleine Vesikel enthält. Sie besitzen vereinzelte Dictyosomen sowie eine Reihe meist kleinerer Mitochondrien. Darüber hinaus zeigen sie Anzeichen endocytotischer Aktivität.

6. Die mitochondrienreichen Zellen zeichnen sich durch laterale Verzahnung sowie ein basales Labyrinth aus und beherbergen zahlreiche Mitochondrien. Sie gleichen morphologisch den exkretorischen Zellen des Rectaldrüsenparenchyms.

7. Die Zellen der basalen Epithels $\mathrm{chich}$ ten sind wenig differenziert. Sie bilden einen lockeren Verband, in dessen Interzellularen häufig weiße Blutzellen gefunden werden.

8. Die Frage nach der funktionellen Bedeutung der Rectaldrüse von Knorpelfischen 
läßt sich mit einer exkretorischen Leistung allein nicht befriedigend beantworten. Neben der Ausscheidung konzentrierter Kochsalzlösungen spielt auch die Sekretion von Schleimsubstanzen eine wichtige Rolle. Während für die Exkretion vorwiegend die Zellen der Drüsenschläuche verantwortlich sind, erfolgt die Schleimsekretion in erster Linie im Zentralkanalepithel.

Die Arbeit wurde mit dankenswerter Unterstützung durch die Deutsche Forschungsgemeinschaft, die Biologische Anstalt Helgoland und das Laboratoire Arago, Banyuls-sur-Mer, durchgeführt. Fräulein I. BAAS danken wir für technische Assistenz.

\section{ZITIERTE LITERATUR}

Barka, T. \& Anoerson, P. J., 1963. Histochemistry. Theory, practice and bibliography. Harper \& Row, New York.

Barrington, E. J. W., 1957. The alimentary canal and digestion. In: The physiology of fishes. Ed. by M. E. Brown. Academic Press, New York, 1, 109-196.

BeNNETT, H. S. 1963. Morphological aspects of extracellular polysaccharides. J. Histochem. Cytochem. 11, 14-23.

BerLin, J. D., 1967. The localization af acid mucopolysaccharides in the golgi complex of intestinal goblet cells. J. Cell Biol. 32, 760-766.

Bernard, G. R. \& Hartmann, J. F., 1960. Cytological and histochemical observations on the elasmobranch rectal gland. Anat. Rec. 137, 340.

Bertin, L., 1958. Appareil digéstif. In: Traité de Zoologie. Ed. par P. P. Grassé. Masson \& Cie, Paris, 13, 1248-1302.

Bierling, F., 1962. Electron microscope observations on the mucous production in human and rat intestinal goblet cells. Actat path. et microbiol. scand. 54, 241.

Bulger, R. E., 1961. Histology and ultrastructure of the rectal gland of Squalus sucklii (acanthias). A. Mtg. Am. Soc. Cell Biol. 1 (24, Abstr.).

- 1963. Fine structure of the rectal (salt-secreting) gland of the spiny dogfish, Squalus acanthias. Anat. Rec. 147, 95-127.

- 1965. Electron microscopy of the stratified epithelium lining the excretory canal of the dogfish rectal gland. Anat. Rec. 151, 589-607.

Burgek, J. W., 1962. Further studies of the rectal gland in the spiny dogfish. Physiol. Zoöl. 35, 205-217.

- \& Hess, W. N., 1960. Function of the rectal gland in the spiny dogfish. Science, N. Y. 131, 670-671.

Doyle, W. L., 1962. Tubule cells of the rectal salt-gland of Urolophus. Am. J. Anat, 111, 223-238.

Florey, H. W., 1960. Electron microscope observations on the goblet cells of the rat colon. Q. Jl exp. Pbysiol. 45, 329.

Frebman, J. A, 1962. Fine structure of the goblet cell mucous secretory process. Anat. Rec. 44,341 .

- 1966. Goblet cell fine structure. Anat. Record 154, 121.

Friend, D. S., 1965. The fine structure of Brunner's glands in the mouse. J. Cell Biol. 25, 563-576.

Helander, H. F., 1962. Ultrastructure of fundus glands of the mouse gastric mucosa. J. Ultrastruct. Res. (Suppl.) 4, 1-123.

Hoskins, E. R., 1917. The development of the digitiform gland and the post-valvular segment of the intestine in Squalus acantbias. J. Morph. 28, 329-365.

ITO, S. \& Winchester, R. J., 1963. The fine structure of the gastric mucosa in the rat. $J$. Cell Biol. 16, 541-577.

JaCobshagen, E., 1937. Mittel- und Enddarm. In: Handbuch der vergleichenden Anatomie der Wirbeltiere. Hrsg. von L. Bolk, E. Göppert, E. Kallius \& W. Lubosch. Urban \& Schwarzenberg, Berlin, Wien, 3, 563-724. 
Kellengerger, E., SChWar, W. \& Ryter, A., 1956. L'utilisation d'un copolymère du groupe des polyesters comme matérial d'inclusion en ultramicrotomie, Experientia 12, 421.

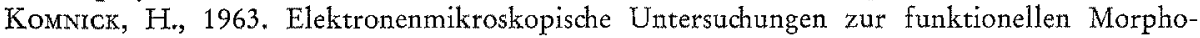
logie des Ionentransportes in der Salzdrüse von Larus argentatus. T. 3. Funktionelle Morphologie der Tubulusepithelzellen. Protoplasma 56, 605-636.

- 1965a. Funktionelle Morphologie von Salzdrüsenzellen. In: Sekretion und Exkretion. 2. wissenschaftliche Konferenz der Ges. Dt. Naturf. u. Arzte, 1964. Hrsg. von K. E. Wohlfarth-Bottermann. Springer, Berlin, 289-314.

- 1965b. Zur Funktion der Rectaldrüse von Haien. Z. Zellforsch. mikrosk. Anat. 66, 28-34.

- 1968. Transportmorphologie der Salzdrüsen von Wirbeltieren. Math.-nat. Habil.-Schr., Bonn.

- \& Wohlfarth-BottermanN, K. E., 1966. Zur Cytologie der Rectaldrüsen von Knorpelfischen. T. 1. Die Feinstruktur der Tubulusepithelzellen. Z. Zellforsh. mikrosk. Andt. 74, $123-144$.

KuR'Tz, S. M., 1964. The salivary glands. In: Electron microscopic anatomy. Ed. by S. M. Kurtz. Academic Press, New York, 97-122.

KusHIDA, H., 1961. A styrene-methacrylate resin embedding method for ultrathin sectioning. J. Electron Microse, 10, 16-19.

MoE, H., 1960. The ultrastructure of Brunner's glands of the cat. J. Ultrastruct. Res, 4, 58.

Neutra, M. \& Leblond, C. P., 1966. Synthesis of the carbohydrate of mucus in the golgi complex as shown by electron microscope radioautography of goblet cells from rats injected with glucose- $\mathrm{H}^{3}$ J. Cell Biol. 30, 119-136.

Newman, B., Borysko, E. \& Swerdlow, M., 1949. Ultramicrotomy by a new method. J. Res. natn. Bur. Stand. 43, 183.

Palay, S. L., 1958. The morphology of secretion. In: Frontiers of cytology. Ed. by S. L. Palay. Yale Univ. Press, New Haven, Conn., 305.

Pearse, A. G. E., 1960. Histochemistry, theoretical and applied. 2nd ed. Churchill, London, $998 \mathrm{pp}$.

PHILport, C. W., 1964. Electrolyt transport and acid mucopolysaccharides of the cell surface. J. Cell Biol. 23, $74 \mathrm{~A}$.

PrXelt, H. L. M., 1908. On the morphology and physiology of the appendix digitiformis in ellasmobranchs. Anat. Anz. 32, 174 178.

Romets, B., 1948. Mikroskopische Technik. 15. Aufl. Oldenburg, München, 695 pp.

Sabatini, D. D., Bensch, K. \& BarRnetT, R. J., 1963. Cytochemistry and electron microscopy. The preservation of cellular ultrastructure and enzymatic activity by aldehyde fixation. J. Cell Biol. 17, 19-58.

Schmor-Nielsev, K., 1960. The salt-secreting gland of marine birds. Circulation 21, 955-967.

- 1965. Physiology of salt glands. In: Sekretion und Exkretion. 2. wissenschaftliche Konferenz der Ges. Dt. Naturf. u. Arzte, 1964. Hrsg. von K. E. Wohlfarth-Bottermann. Springer, Berlin, 269-288.

SEDAR, Q. W., 1964. Stomach and intestinal mucosa. In: Electron microscopic anatomy. Ed. by S. M. Kurtz. Academic Press, New York, 123-148.

SheArman, D., \& Murr, A., 1960. Observations on the secretory cycle of goblet cells. Q. $l l$ exp. Physiol. 45, 337.

Sirva, D. G., 1966. The fine structure of multivesicular cells with large microvilli in the epithelium of the mouse colon. J. Ultrastruct. Res. 16, 693-705.

WETZEL, M. G., WETzel, B. K. \& SpICER, S. S., 1966. Ultrastructural localization of acid mucosubstances in the mouse colon with iron-containing stains. J. Cell Biol. 30, 299-315.

WhaleY, W. G., 1966. Proposals concerning replication of the Golgi apparatus. In: Probleme der biologischen Reduplikation. 3. wissenschaftliche Konferenz der Ges. Dt. Naturf. u. Arzte, 1965. Hrsg. von P. Sitte. Springer, Berlin, 340-371.

Wohlfarth-BotTermann, K. E., 1957. Die Kontrastierung tierischer Zellen und Gewebe im Rahmen ihrer elektronenmikroskopischen Untersuchung an ultradünnen Schnitten. Naturwissenschaften 44, 287-288. 